\title{
A REFLECTIVE STUDY OF ALZHEIMER'S CAREGIVERS
}

By

KEVIN PETRONELA JUOZAPAVICIUS

Bachelor of Science

Mary Washington College

Fredericksburg, Virginia

1998

\author{
Submitted to the Faculty of the \\ Graduate College of the \\ Oklahoma State University \\ in partial fulfillment of \\ the requirements for \\ the Degree of \\ MASTER OF SCIENCE
}

May, 2000 


\section{A REFLECTIVE STUDY OF ALZHEIMER'S CAREGIVERS}

Thesis Approved:

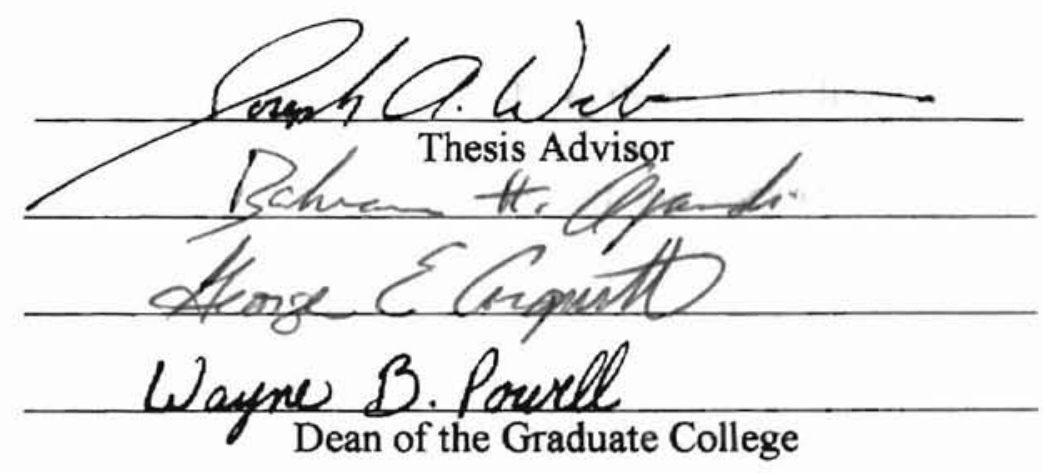




\section{ACKNOWLEDGEMENTS}

I wish to express my appreciation to my major advisor, Dr. Joseph Weber for his help and support. Dr. Weber's knowledge, understanding, advice and friendship were invaluable sources of strength throughout the course of my research. I would also like to thank the other members of my thesis committee, Dr. Ed Arquitt and Dr. Bahram Arjmandi for their support and expert advice in this research study.

I would also like to thank my parents, Albert and Sharon, for their love and encouragement through this process. In addition, I would like to thank my brother, Justin for his confidence in me. Finally, I would like to thank my bulldog, Eve for her unshakeable companionship and tolerance through my research. 


\section{TABLE OF CONTENTS}

$\begin{array}{lll}\text { Chapter } & \text { Page }\end{array}$

I. INTRODUCTION $\ldots \ldots \ldots \ldots \ldots \ldots \ldots \ldots \ldots \ldots \ldots \ldots$

Statement of the Problem ................... 3

Purpose of the Study ........................ 4

Objectives .......................... 4

Theoretical Orientation $\ldots \ldots \ldots \ldots \ldots \ldots \ldots \ldots \ldots \ldots$

Definition of Terms $\ldots \ldots \ldots \ldots \ldots \ldots \ldots \ldots \ldots \ldots$

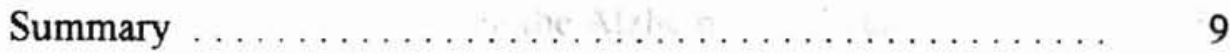

II. REVIEW OF THE LITERATURE $\ldots \ldots \ldots \ldots \ldots \ldots \ldots \ldots \ldots \ldots$

An Overview of Alzheimer's Disease $\ldots \ldots \ldots \ldots \ldots \ldots \ldots$

Demographics .......................... 10

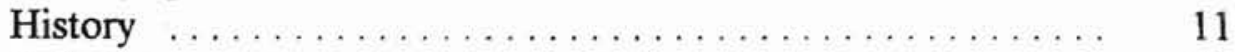

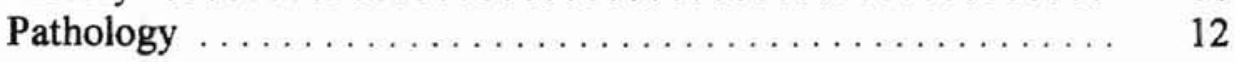

Diagnosis . . . . . . . . . . . . . . . . . . . . . . 13

Stages of Alzheimer's Disease . . . . . . . . . . . . . . . 14

Treatments for Cognitive Symptoms . . . . . . . . . . . . 15

Current Research ......................... 17

Alzheimer's Caregivers . . . . . . . . . . . . . . . . . 18

Caregiver Demographics ...................... 18

Differentiating the Alzheimer's Caregiver . . . . . . . . . . . 18

Caregiver Resources ............................ 19

Summary ........................... 21

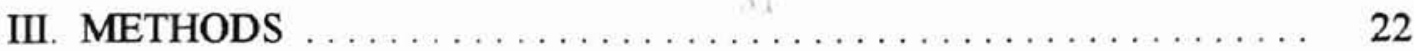

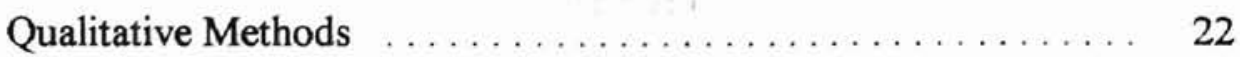

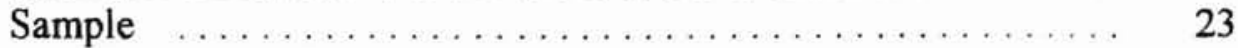

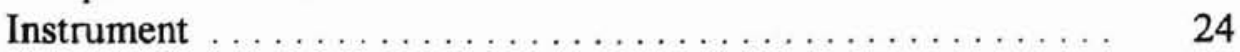

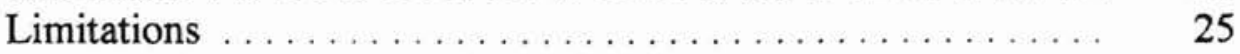

IV. A REFLECTIVE STUDY OF ALZHEIMER'S CAREGIVERS . . . . . 26

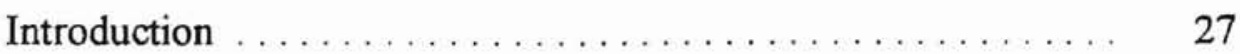




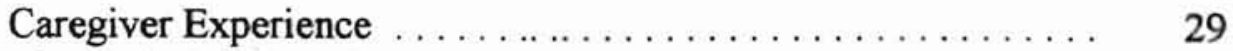

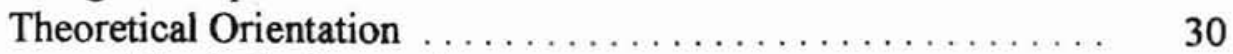

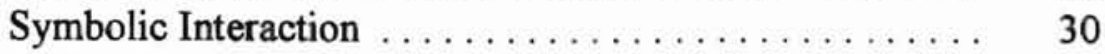

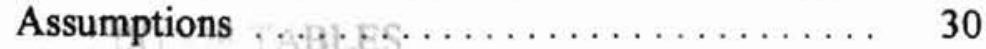

Time Orientation $\ldots \ldots \ldots \ldots \ldots \ldots \ldots \ldots, 31$

Relevant Literature ......................... 32

An Overview of Alzheimer's Disease ............ 32

Demographics ......................... 32

History $\ldots \ldots \ldots \ldots \ldots \ldots \ldots \ldots \ldots, 33$

Pathology ....................... 33

Diagnosis ...................... 34

Stages of Alzheimer's Disease . . . . . . . . . . $\quad 35$

Alzheimer's Caregivers .................... $\quad 36$

Caregiver Demographics ............... 36

Differentiating the Alzheimer's Caregiver ..... 36

Caregiver Resources .................. 37

Summary ........................... 39

Purpose of the Study . . . . . . . . . . . . . . . . . $\quad 39$

Objectives ................................ 40

Methods ............................... 40

Sample ........................... 40

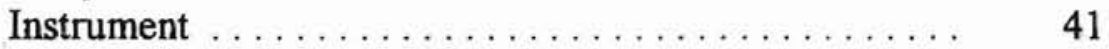

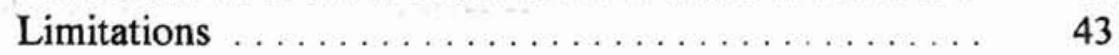

Results ............................... 43

Discussion ............................. 56

Implications . . . . . . . . . . . . . . . . . . . . . . 60

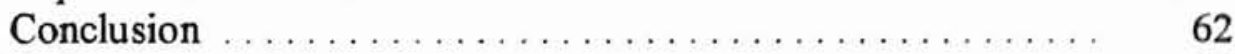

References .............................. 64

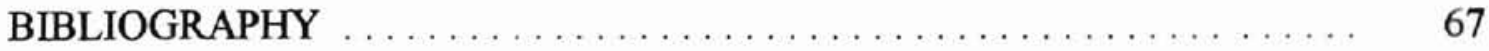

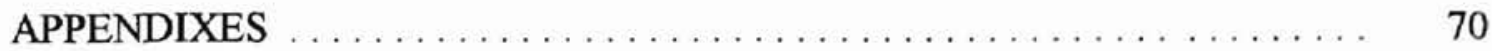

APPENDIX A - RESEARCH INSTRUMENT $\ldots \ldots \ldots \ldots \ldots \ldots \ldots \quad 71$

APPENDIX B - ANALYSIS OF RESEARCH OBJECTIVES AND TABLES $\ldots \ldots \ldots \ldots \ldots \ldots \ldots \ldots \ldots \ldots$

APPENDIX C - INSTITUTIONAL REVIEW BOARD FORM . . . . . 104 


\section{LIST OF TABLES}

$\begin{array}{lll}\text { Table Page } & \text { Pa }\end{array}$

1. Descriptive Characteristics of Former Alzheimer's Caregivers ....... 90

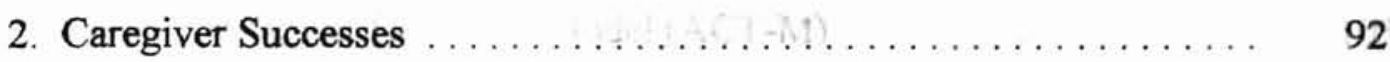

3. Caregiver Regrets ......................... 93

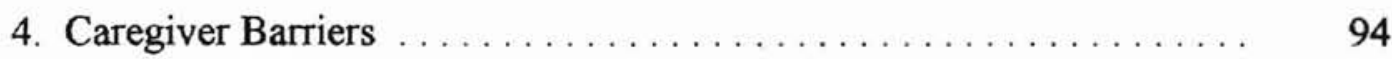

5. Issues Following Death $\ldots \ldots \ldots \ldots \ldots \ldots \ldots \ldots \ldots \ldots$

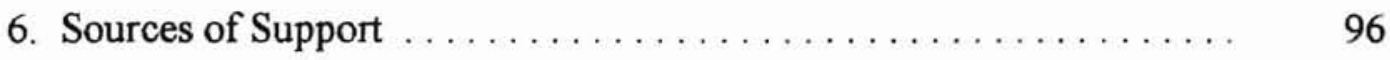

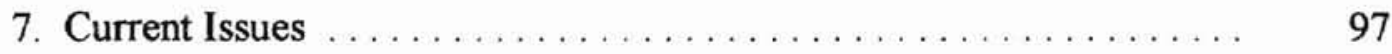

8. Perceptions During the Caregiver Experience $\ldots \ldots \ldots \ldots \ldots \ldots \quad 98$

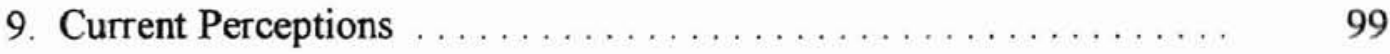

10. Perception Comparison $\ldots \ldots \ldots \ldots \ldots \ldots \ldots \ldots \ldots \ldots \ldots$

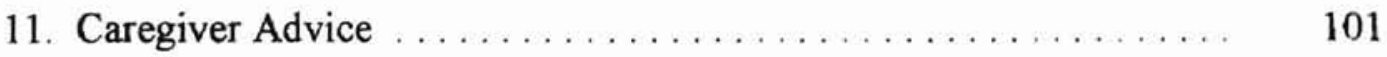




\section{LIST OF FIGURES}

$\begin{array}{lll}\text { Figure } & \text { Page }\end{array}$

1. Caregiver Reflection Model $\ldots \ldots \ldots \ldots \ldots \ldots \ldots \ldots \ldots \ldots \ldots, 102$

2. Alzheimer Caregiver Transition Model (ACT-M) $\ldots \ldots \ldots \ldots \ldots \ldots \ldots$ 


\section{Chapter 1}

Introduction

The demographic structure of America has traditionally taken the shape of a standard pyramid. The broad base of this pyramid has represented the population segment in its mid twenties and younger. The narrower apex of the pyramid has signified those individuals over the age of sixty-five (Blieszner \& Bedford, 1994). However, over the last decade, America has experienced a demographic transition which has altered this traditional depiction. This transition is a movement from a predominantly younger to a predominantly older population and is due to a combination of low fertility and low mortality rates (Attarian, 1999). If this transition continues, it is predicted that by the year 2025 , the traditional population pyramid will begin to invert, placing the over sixty-five group as the largest segment of the pyramid (Blieszner \& Bedford, 1994).

One of the major contributors to this demographic inversion is a significant increase in life expectancy over the last century. In 1900s America the average life expectancy was less than fifty years. By the 1950 s the life expectancy had increased to around seventy years of age. Today, the life expectancy for females is seventy-nine years and seventy-three years for males (Meier \& Morrison, 1999).

This increase in life expectancy has traditionally been cheered by a society whose main focus on aging has been the elongation of life. Recently the cheers have been muffled, however as society is forced to deal with the fact that with increased age there is also increased risk for disease and dependency. Although medical advances have been able to increase life expectancy, they have been unable to find the answers to many of the diseases which jeopardize the quality of life for those extended years. The current and projected demographic structure creates a heightened sense of urgency to solve these problems before society is faced with them in epidemic proportions

One of the most prominent of the unsolved problems facing the elderly is Alzheimer's disease. Alzheimer's disease is the most common form of dementia in the 
elderly and is characterized pathologically by cerebral atrophy, neurofibrillary degeneration and senile plaques (Sloane, 1998). The onset of Alzheimer's disease occurs between the ages of forty and ninety, with the greatest risk coming after the age of sixty-five. In fact, for every 5 years beyond sixty-five, the risk of Alzheimer's disease doubles (Rose, 1999),

Alzheimer's disease is classified as a degenerative disease which manifests itself as random forgetfulness. This forgetfulness progresses to more severe memory loss which then leads to confusion, loss of speech and mobility, paranoia, hallucinations and behavioral problems (Khachaturian, 1997). In the end the victim is left completely helpless, trapped in a body that no longer functions, recognizes, or remembers.

The National Institute on Aging estimates that there are currently 4 million victims of Alzheimer's disease in America alone. It is projected that by the year 2050 this number could more than triple (Sikanovski, 1998). Because of the overwhelming nature of these figures, Alzheimer's disease has become one of the main areas of focus for aging researchers.

Alzheimer's research can be approached from a medical standpoint or from a social standpoint. The medical approach is focused on the causative, preventive and curative factors of the disease. It was estimated that the government spent over $\$ 350$ million in 1998 engaged in such research (Joyner, 1998). Although studies have reported optimistic findings based on genetic linkages, the cure for the disease remains elusive (Sikanovski, 1998).

The second approach to Alzheimer's research concerns the social aspects of the disease. Social researchers concerned with Alzheimer's disease place their focus on how to best care for the Alzheimer's victim (Sikanovski, 1998). The scope of their research extends beyond the direct victims themselves; to include the families and friends who often form the crucial supporting networks. It is these individuals who are often faced with the responsibility of caring for a loved one and must themselves struggle to survive the disease. A major component of such research is to explore the needs and experiences of 
these caregivers in an attempt to establish better ways of coping with and managing the progressively deteriorating stages of Alzheimer's disease.

\section{Statement of the Problem}

Estimates indicate that there are at least 4 million victims of Alzheimer's disease in America today (Sikanovski, 1998). Further estimates show that of these 4 million victims, over half will be cared for at home (Rose, 1999). The caregivers for these victims are family and friends who have chosen to alter their lives and take on the responsibility for their loved one's care. In a very real way, by adopting the role of the caregiver, these individuals also become victims of the disease, as they must struggle themselves to survive it.

The struggle these caregivers face is immense, trying both their mental and physical capabilities and exhausting their emotional reserves. Researchers have acknowledged the enormity of the caregiver burden and have focused their attention on finding better ways to cope with and manage the caregiver experience. Effective strategies, educational tools, support services and outreach organizations have been developed to help guide the caregiver from the beginning of the disease, through its three stages, and finally to their loved one's death and their own grief.

This cycle of support is crucial for Alzheimer's caregivers to successfully survive the disease. However, what happens to the caregiver once he or she is outside the cycle? The individual is still left with a variety of emotions, thoughts and memories which must be sorted out and come to terms with. During this renegotiation process, the individual will be continuously reflecting on their role as caregiver. The contents of these reflections are a valuable asset for other caregivers to learn from and use throughout their own experiences.

It is also important to recognize the significance of the transition period out of the caregiver role. Since the death of their loved one is an event that every caregiver will eventually face, it is important to explore the stages that follow this event. This 
exploration will establish facts to help extend the cycle of support through the time when the caregiver must renegotiate their life and come to terms with the past.

\section{Purpose of the Study}

The purpose of this study is to explore the issues faced by Alzheimer's caregivers some time after the death of the care recipient. The caregivers will be asked to reflect on both their caregiving experience and the time frame following its conclusion. The information from these reflections will be used to explore and identify the stages involved in the transition out of the caregiver role. The results of this study will serve as a valuable asset for caregivers at the beginning, middle and end of their caregiving experiences.

\section{Objectives}

This study will be guided by the following objectives:

1.) To generate a caregiver profile from the background information collected from each caregiver.

2.) To identify and explore the factors which precipitated the beginning of the caregiver role for each caregiver.

3.) To record and analyze the reflections conveyed by each caregiver.

4.) To use the reflective information to identify the stages which comprise the transition out of the caregiver role.

\section{Theoretical Orientation}

The focus of this study centers around the reflections of Alzheimer's caregivers on their roles and experiences. This focus places the caregiver in the position of expert and assigns the researcher the tasks of listening and understanding. In order to attain this understanding, the researcher must put herself in the position of the caregivers in an attempt to visualize the reflections through their eyes. Through this transposition, the 
researcher can better create a frame of meaning for a caregiver's actions and behaviors, which will facilitate the understanding and analysis of each caregiver's reflection.

Symbolic interactionism will serve as the theoretical basis to guide the researcher in the formation of such meaning. From its beginning, symbolic interactionism has focused on exploring ways to understand different situations and behaviors (LaRossa \& Reitzes, 1993). This framework attempts to provide a method for researchers to understand how subjects define certain situations and how those definitions affect observed behaviors (LaRossa \& Reitzes, 1993). Symbolic interactionism will aid the researcher in first understanding the caregivers perspective to help understand the information conveyed by each caregiver.

This study will utilize two assumptions made by symbolic interactionism which are directly applicable to reflective caregiver research. First, to understand human behavior one must understand the meaning of the observed behavior to the actor (Klein \& White, 1996). The researcher must attempt to identify a frame of meaning for each caregiver in order to accurately analyze each reflection. This assumption also serves as an important guideline in alerting the researcher that each caregiver's frame of meaning will vary. Therefore, the information contained in each reflection must be differentiated according to that meaning.

The second assumption of relevance is that actors define a given situation and consequently define the problems which arise from the situation and the steps they take to solve those problems (Klein \& White, 1996). It is critical in this study to identify how each caregiver viewed their particular situation in order to better understand behaviors and actions during and after the caregiving experience. For example, if one caregiver views a situation as problematic, the ensuing behavior will differ from another caregiver who views the same situation less negatively. The researcher will need to be aware of such variations in order to avoid drawing erroneous conclusions from the caregivers' reflections 
Inherent in both of these assumptions and in the nature of this study is the concept of role. The symbolic interactionist framework builds many of its tenets around the notion of an actor's role, or place in a situation, and the action of taking on that role (Klein \& White, 1996). In this study, all of the subjects will have experienced some precipitating event which resulted in the taking on of the caregiver role. With this role adoption, the individual will also have assumed the prescribed set of rules and behaviors governing the role of caregiver.

The inherent rules and behaviors in a given role correspond with the expectations for the fulfillment of that role. Such expectations are both personal, held by the subjects themselves, and public (Klein \& White, 1996). Each caregiver had expectations of themselves and of the level of care for their loved ones. A key component in each reflection will be a sense of whether the caregivers felt they met their expectations or whether they fell short of these goals. A realization of this sense gives the researcher a potential origin or explanation for other feelings and behaviors conveyed in each reflection.

Along with the private expectations held by each caregiver, were also those expectations placed on the caregiver by individuals outside the role. These expectations will have either coincided or conflicted with those held by the caregiver. If the expectations were in conflict, this could have created a source of added tension and stress for the caregiver which might help the researcher elucidate certain behaviors and reactions communicated in a reflection.

The idea of role serves as the parent concept to a number of other elements useful in qualitative research. Two such elements which are particularly applicable to this study are role strain and role conflict. Role strain occurs when an individual lacks the necessary resources to properly enact a role. Role conflict describes a situation where the expectations of two separate roles held concomitantly by an individual overlap or contradict each other (Klein \& White, 1996). 
In analyzing the caregivers' reflections, identifying the presence of role strain will help the researcher better understand certain facets of a particular account. Some potential resources which the caregiver might have lacked include time, money, support networks and energy. Even with this short list, it is easy to see how a deficiency in any one of these factors could greatly affect the caregiver experience (Figure 1).

The issue of role conflict plays an equally important part in the experiences of a caregiver. The researcher should be aware of this element in accounts given by caregivers in which they indicate the maintenance of two usually exclusive roles. For example, the subject can be both the father of a young child and the son of a parent with Alzheimer's. In his position as father he must fulfill the role of taking care of his child. However, he must also now fulfill the role of caregiver to his parent. Each role has full- time demands, yet the individual must meet the expectations of both. In such a situation, role conflict exists and may have a great impact on both an individual's outlook and behavior.

Finally, there are two time-oriented concepts from symbolic interactionism which are useful for reflective research. The first of these concepts is termed the symbolically reconstructed past. This refers to the time period where the actor renegotiates past stages and events in his or her life (Knipscheer, 1988). This concept serves as the basis of each caregiver's reflection. Each reflection is comprised of renegotiations of past experiences by the subjects to have current value and meaning in their present lives.

The second temporal concept is the social-structural past. This concept encompasses the notion that present and future behaviors and actions are governed by past events (Knipscheer, 1988). The impact of the caregiver experience on each subject will affect the transition period out of the caregiver role. The duration, actions and emotions of the stages will be impacted in various ways according to each caregiver's experience The researcher must analyze the data to identify the impact of the caregiver experience on each of these elements. 
The symbolic interactionist framework is a powerful force in research because it focuses on understanding behavior through the eyes of the actor instead of the observer. In this study, the actors are former Alzheimer's caregivers who have been asked to recount both their experiences as caregivers and their experiences as they move out of the caregiver role. The researcher will utilize the theoretical basis of symbolic interactionism to analyze each reflection from the perspective of the caregiver. This method will allow the researcher to draw conclusions which are accurate and relevant to both the research and caregiver communities.

\section{Definition of Terms}

Definitions of key terms in this study include:

Alzheimer's disease - Alzheimer's disease is a degenerative disease affecting the brain and is the most common cause of dementia in the elderly.

Caregiver - A caregiver is any person who provides direct care for another individual. In this study, the term caregiver will refer specifically to an individual who provided direct care for an Alzheimer's victim.

National Institute on Aging (NIA) - The NIA is one of 13 institutes which comprise the National Institute of Health (NIH). It is responsible for the conduct and support of biomedical, social and behavioral research, training, health information dissemination and other programs associated with the aging process and the diseases and special problems of the aged.

Reflection - Reflection, in this study, refers to a reconsideration and rumination of past events for the purpose of making them relevant to current life.

Role - The term role refers to the place an individual has in a given situation, i.e. caregiver role.

Symbolic Interaction - Symbolic interaction is a theoretical framework which attempts to provide a method for researchers to understand how subjects define certain situations and how those definitions affect observed behaviors. 
Transition - Transition refers to the passage from one state, place or stage to another. Summary

Alzheimer's disease is a severe problem facing the older segment of the population. This disease attacks not only the primary victim, but it also devastates the Alzheimer's caregiver as well. Current research is directed at two aims: finding curative and preventative measures for the disease and finding ways to help caregivers better manage and cope with their situations. This study, focusing on the reflections of Alzheimer's caregivers, will provide an important informational tool for other caregivers to use throughout the disease course and in the transition out of the caregiver role. 


\section{Chapter 2}

\section{Review of Literature}

Before research can be conducted about a certain topic, a thorough foundation must be laid concerning the primary themes in the study. In this study, the researcher will attempt to look through the eyes of the Alzheimer's caregivers to understand their reflections from their own personal perspectives. The first section in this chapter will present a brief yet thorough background on Alzheimer's disease. The next section will explore several issues dealing with caregiving. The final section will introduce the concept of retrospective research and consider its usefuiness and applicability.

An Overview of Alzheimer's Disease

\section{Demographics}

The National Institute on Aging estimates that there are currently 4 million victims of Alzheimer's disease in America alone (Sikanovski, 1998). The leading risk factor for this disease is old age, with a 1 in 3 chance of development after age eighty-five (Sloane, 1998). This statistic is significant because it is the eighty-five and older group that is the fastest growing population segment in the U.S. (Khachaturian, 1997). If this demographic trend continues and the disease maintains its present course, estimates indicate that the number of Alzheimer's victims in the US could more than triple to over 14 million by the year 2050 (Sikanovski, 1998).

Alzheimer's disease has placed an enormous financial burden on the US. It has been estimated that this disease costs the country $\$ 67.3$ billion annually (D'Epiro, 1998) This figure includes the care provided for Alzheimer's victims, the costs of medical and social research and the money American businesses lose from victims and caregivers who can no longer work (Joyner, 1998). Amazingly, this number is only projected to increase as care standards improve and the average duration of the disease is extended from eight years to as long as twenty years (Khachaturian, 1997). 


\section{History}

Although Alzheimer's disease has become associated with the modern decades, it is in reality a disease of antiquity. Researchers have identified accounts of the then unnamed and mysterious disease dating back to Ancient Greece and Rome (Khachaturian, 1997). Chroniclers of these civilizations wrote about a disease which makes people forget their pasts and takes away their recognition of family, friends and possessions. Because of its outcome, this disease was considered by many ancient peoples to be far worse than any other bodily affliction (Brothwell \& Sandison, 1967).

Various other accounts can be traced throughout the writings of later civilizations. Elizabethan records, for example, have been shown to contain descriptions of what is now called Alzheimer's disease. The most famous example from this era is King Lear; who upon close examination of the literature seems to exhibit symptoms remarkably identical to those currently associated with Alzheimer's disease (Khachaturian, 1997).

Despite the extensive writings on this strange illness, Alzheimer's disease was not identified as a distinct disease until the early 1900s (Khachaturian, 1997). In 1901, a fiftyone year old woman, Auguste D., was admitted into the Hospital for the Mentally Ill and Epileptics in Frankfurt, Germany (Enserink, 1998). The hospital's senior physician, Alois Alzheimer, examined Auguste and was amazed by her symptoms. Alzheimer reported that Auguste was disoriented; showed reduced levels of comprehension and memory; displayed erratic behavior; experienced paranoia and hallucinations and was suffering from pronounced psychosocial impairment (Maurer, Volk \& Gerbaldo, 1997).

In 1906, Auguste D. died and Dr. Alzheimer was given permission to autopsy her brain. In his results, Alzheimer documented finding substances which he referred to as "odd brain-tissue growths" (Khachaturian, 1997). He presented these results later that year at the 37th Conference of South-West German Psychiatrists in Tubingen, Germany. In 1910, Kraepelin, a German psychiatrist who had worked on the Auguste D case, used 
the term "Alzheimer's disease" for the first time in a psychiatry handbook to describe Alzheimer's findings (Enserink, 1998).

In September 1997, neuropathologist Manuel Graeber led a team of scientists in search of the slides Dr. Alzheimer had made of Auguste's brain tissue. They succeeded in finding over 250 of the slides at the University of Munich in Germany. After examining the slides, the team was able to identify Dr. Alzheimer's "odd brain-tissue growths" as amyloid plaques and neurofibrillary tangles; now known as the two classic pathological signs of Alzheimer's disease (Enserink, 1998).

\section{Pathology}

Since the documentation of the Auguste D. case, the pathology of Alzheimer's disease has attracted much scientific interest. This attention has led to the successful identification of two cardinal pathologic features found in the brain of every Alzheimer's victim. These two features are neuritic plaques and neurofibrillary tangles (Selkoe, 1997). Recent research has identified a third lesion, termed an AMY plaque, which may prove to be another identifying feature of Alzheimer's disease (Sikanovski, 1998).

The neuritic plaques, characteristic of Alzheimer's disease, are extracellular masses of beta-amyloid filaments. The other cardinal feature in the brain, neurofibrillary tangles are intracellular masses of altered protein (Selkoe, 1997). The principle component in these plaques is the beta-amyloid peptide. In the brains of normal individuals, betaamyloid deposits are found sparingly. In contrast, in an Alzheimer's brain, there is an increase in production and deposition of this peptide (Jay, 1997).

The buildup of beta-amyloid peptides in the brain stimulates an inflammatory-like response by the tissue. This response causes neuronal injury which leads to synaptic loss and multiple neurotransmitter deficits. Scientists often use the analogy that beta-amyloid deposits are to Alzheimer's disease what cholesterol buildup is to heart disease (Selkoe, 1997). 


\section{Diagnosis}

Despite research advancements, it is still impossible to be $100 \%$ accurate in diagnosing a patient with Alzheimer's disease. However, new diagnostic tools and evaluation techniques allow physicians to decrease their margin of error for misdiagnosis to $10-15 \%$ (Sikanovski, 1998). It is critical that the patient be given an accurate diagnosis as early in the disease as possible to maximize quality of life and delay long-term care placement (Gonzalez, 1999).

The diagnostic process for Alzheimer's disease identification involves many multidimensional procedures. The physician must first obtain a detailed history of the patient's cognitive and behavioral changes, focusing on their progression over time (Geldmacher \& Whitehouse, 1996). This history should be collected from the patient as well as from a spouse or other close relative to receive the most accurate account possible. This information will serve as a foundation for the physician to use in conjunction with further diagnostic evaluations (Gonzalez, 1999).

From the information collected in the patient's history, the physician can answer several questions which will help direct the diagnosis. One of the most important of these questions is whether the individual's cognitive changes have presented a barrier to normal levels of functioning, and thereby inhibiting quality of life. This question is important in attempting to differentiate the effects of normal aging versus those of a pathological condition. Cognitive function does decline with age. However, the changes would not be drastic enough to impact overall quality of life (Gonzalez, 1999).

The next phase in the diagnostic procedure would be a physical and mental examination of the patient. The physical exam is important to identify other factors which could be causing the patient to exhibit Alzheimer's-like symptoms. The mental examination usually utilizes the Folstein MiniMental State Examination (MMSE) to assess such factors as memory, orientation, motor skills and judgment. The results from this test 
do not rule out or confirm an Alzheimer's diagnosis. Instead, they serve as a significant tool to be used in conjunction with the other observations (Gonzalez, 1999).

After evaluating all of the test results together with a patient's history, a physician can make a possible, probable, or definite diagnosis of Alzheimer's disease (Gonzalez, 1999). In many cases, the diagnosis is not Alzheimer's disease, rather it is a curable condition such as malnutrition or depression. However, when Alzheimer's disease is indicated, the patients and their families can then take the steps needed to maximize quality of life.

\section{Stages of Alzheimer's Disease}

Every individual affected by Alzheimer's disease will have their own unique experiences with the course of the disease. However, researchers have identified some common thematic changes typical of the disease course, which they have grouped into three stages following the progression of the disease. The early stage of the disease is characterized by exhibitions of mild impairment. As cognitive capacity worsens, individuals proceed into the middle stage of the disease where they are moderately impaired. The late stage of the disease is characterized by severe to total impairment, leading eventually to the victim's death (D'Epiro, 1998).

In the early stage of Alzheimer's disease the victim shows signs of memory loss and has difficulty performing complicated cognitive functions. At the beginning of this stage the person may be able to function properly and safely in their job. However, by the middle and end parts of this stage, the victim will be a danger to himself and others. Driving will also become problematic and for everyone's safety an Alzheimer's victim should stop driving (D’Epiro, 1998).

By the middle stage of this disease the victim struggles with both written and spoken language performance (D'Epiro, 1998). This stage is further characterized by the repetitive asking of questions and the inability to express oneself appropriately in conversation (Gonzalez, 1999). As the moderate impairment worsens, victims begin 
losing the ability to care for themselves, neglecting even basic hygienic habits. During this stage the individual may also experience hallucinations and paranoia as well as problematic behaviors such as rummaging, wandering and pacing (Khachaturian, 1997).

In the late stage of Alzheimer's disease, the person has become severely impaired to where assistance is required with all of the basic needs. The memory is gone and the victim no longer recognizes family or friends. Eventually the person will lose auditory comprehension and any ability to speak (D'Epiro, 1998). The victim develops eating difficulties and becomes frail and highly susceptible to falls and other illnesses and injuries. Incontinence becomes a problem and the body's muscles and joints become rigid. Eventually, the body and mind completely shut down. Some typical "causes" of death for an Alzheimer's victim are aspiration pneumonia, bacterial infections, general debility, falls, and fractures (White, 1997).

\section{Treatments for Cognitive Symptoms}

Despite the prevalence of Alzheimer's disease in today's society and the vast research devoted to its study, no cure has yet been found for the disease. Science has however been successful in finding drugs to help extend the quality of life for an Alzheimer's victim. These drugs temporarily restore a portion of the functioning lost to the disease (Sloane, 1998).

There are currently two Alzheimer's drugs available on the market. The first of these, tacrine (Cognex), was approved by the Food and Drug Administration (FDA) in 1993 and the second, donepezil (Aricept), was licensed in 1997 (D'Epiro, 1998). The FDA is currently testing two other very similar drugs, metrifonate and rivastigmine, which are showing positive results (Sloane, 1998).

Both donepezil and tacrine are cholinesterase inhibitors, aimed at smoothing the communication process between affected neurons in the brain. These inhibitors slow the breakdown of acetylcholine, the brain chemical involved in memory and learning, allowing it to remain at a neuronal synapse for a slightly longer period of time (Sahelian, 1999). 
This extended stay enables cells to communicate just long enough to convey a message (Khachaturian, 1997). Through this mechanism, these drugs slow the cognitive decline in Alzheimer's patients, with a good response being the return of a patient to their functioning level 6-12 months before the medication was started (Sloane, 1998).

Although both drugs appear to be equally effective, donepezil has less secondary effects than tacrine. Tacrine, unlike donepezil, is potentially hepatoxic requiring the patient to have bi-weekly liver function tests. In contrast, the side effects for donepezil are usually only diarrhea, nausea, and vomiting. Also, because donepezil has a longer halflife than tacrine, its dosage is only once a day (Gonzalez, 1999).

Besides these cholinesterase inhibitors, researchers are also experimenting with several other drug therapies for Alzheimer's disease. One such experiment involves the usage of antioxidants, like Vitamin E, to reduce oxidative nerve cell damage (Sikanovski, 1998). Studies conducted using Vitamin E supplementation show positive effects on extending a patient's ability to perform daily activities. Although no significant improvements have been documented, preliminary results show a slowing of the deterioration process (Sikanovski, 1998).

Research has also been conducted using nonsteroidal anti-inflammatory drugs (NSAIDs) such as aspirin and ibuprofen. Results show an association between NSAID use and a lower incidence of dementia. However, because of the risk of toxicity from NSAIDs, they cannot yet be recommended for use in combating Alzheimer's disease (Sloane, 1998).

A third major research focus considers the relationship between estrogen and Alzheimer's disease. The data that has been collected so far shows that women who take estrogen are $50 \%$ less likely to develop Alzheimer's disease then those who do not (D'Epiro, 1998). Scientists believe that this reduced risk may be due to estrogen's ability to prolong neuronal survival and perhaps limit the amount of beta-amyloid deposited in the brain. The only major opposition to advocating Estrogen Replacement Therapy 
(ERT) comes from evidence linking it with an increased risk for breast cancer (D’Epiro, 1998).

\section{Current Research}

One of the most promising areas of research for a cure to Alzheimer's disease is being undertaken by researchers from the Elan Corporation. They are testing the long held theory that the pathological amyloid plaques in the brain are responsible for neuron death and subsequent cognitive declines. The subjects of the experiments are transgenic mice which have been genetically engineered to develop a pathology similar to that seen in human victims of Alzheimer's disease. Scientists are immunizing the mice with AN-1792, the peptide responsible for initiating the accumulation of amyloid in the brain. Preliminary findings suggest that such an immunization may not only prevent the development of Alzheimer's disease but may actually clear plaques which have already formed in the brain (www. alz.org, 1999).

Another promising line of research involves the botanical extract Huperzine A. This extract, long a staple of Chinese folk medicine, is derived from the club moss Huperzia serrata. Huperzine A works like tacrine by inhibiting the activity of the enzyme which breaks down the brain chemical acetylcholine. Several tests show that this extract improves memory, cognition and behavioral functions in the cognitively impaired elderly. Although Huperzine A is being taken by some Alzheimer's patients, further research is needed to learn more about this extract (Sahelian, 1999).

The other major area of Alzheimer's research involves the social aspects of the disease. This research focuses on the development of optimal caregiver methods and resources. This research is concerned with improving the quality of life for both Alzheimer's victims and their caregiver (Sikanovski, 1998). A major goal of such research is finding ways of helping caregivers cope with the burdens they face by providing educational tools, support networks and emotional outlets. 


\section{Alzheimer's Caregivers}

\section{Caregiver Demographics}

Demographic statistics show that the average age of a care recipient is seventyseven and the average age of a caregiver is forty-six. Further data indicate that the vast majority $(85 \%)$ of caregivers are related to the recipient, with only $15 \%$ being someone outside the family (Ten-Kate, 1997). Focusing particularly on Alzheimer's care data, it is estimated that of the 4 million victims with this disease over half will be cared for at home by either a spouse or a child (Rose, 1999).

\section{Differentiating the Alzheimer Caregiver}

Any form of caregiving is an exacting process, which taxes a person physically. emotionally, financially and spiritually. Although every caregiver situation is unique, researchers have identified some common problems faced by Alzheimer's caregivers as a whole. These problems differentiate the Alzheimer caregiver from other caregivers through prevalence and severity.

Perhaps the most significant problem faced by Alzheimer's caregivers is the lack of reciprocity that exists in their situation. In other forms of caregiving the care recipient can often attempt to reciprocate the care they receive through words and actions of gratitude, helpfulness, cooperation and support. In contrast, with Alzheimer's caregiving, by the middle and late stages of the disease when the care is the most intensive, the patient can often no longer express gratitude or helpfulness. Instead, the care recipient is often full of anger and resentment toward the caregiver and becomes belligerent, uncooperative and even violent (Burns, Eisdorfer, Gwyther, \& Sloane, 1996). This imbalance where the caregiver feels that all they do is give without receiving anything back, often leads to higher levels of anger, resentment and frustration in the Alzheimer's caregiver.

Another major problem faced by Alzheimer's caregivers is depression. Although depression is often present in any type of caregiver situation, research indicates that it is more predominant and severe in an individual caring for someone with Alzheimer's 
disease (Meshefejan, McCusker, Bellavance \& Baumgarten, 1998). Compounding this statistic is the fact that many severely depressed Alzheimer's caregivers deny their condition or refuse or overlook getting treatment (Gannon, 1994).

Research has also shown that sons and daughters who are both caregivers to a parent with Alzheimer's and employed report higher levels of emotional, physical and financial strain than do others in a similar situation who care for physically impaired parents (Clipp \& George, 1993; Starrels, Ingersoll-Dayton, Dowler \& Neal, 1997). Alzheimer's caregivers also give more indications that the caregiving process impacts their personal and professional lives to a more negative extent when compared with other caregivers (Scharlack, 1989; Starrels et al, 1997).

A final key distinguishing feature of the Alzheimer caregiver relates to personal health issues. The role of Alzheimer's caregiver has been linked with higher incidences of health problems than levels seen in other caregivers (Ostwald, Hepburn, Caron, Burns \& Mantell, 1999). Some very common health problems affecting an Alzheimer's caregiver include sleep disorders, anxiety, chronic fatigue, hypertension and cardiovascular disease (Burns et al, 1996). Many of these develop because the caregiver does not take any time for themselves to eat right, exercise, relax and rest. The Alzheimer's caregiver becomes so burdened by their situation that they lose sight of their own importance. Because of this, it is unfortunately becoming more common to see the Alzheimer's caregiver become the first casualty of the disease.

\section{Caregiver Resources}

There is no resource that can serve as a cure-all for the problems faced by an Alzheimer's caregiver. However, there are various programs which have been designed to help ease the caregiver burden and/or allow the caregiver some temporary relief from their situation. It is vital to the physical, mental and emotional preservation and well-being of the caregiver that they are made aware of the resources available and are informed about the importance of their use. 
There are several major organizational resources of which every Alzheimer's caregiver should be made aware. The first, and perhaps most important, is the Alzheimer's Association. This organization is made up of over 200 chapters located throughout 50 states and has 2,000 Alzheimer's support groups (Robinson, 1998). The Alzheimer's Association can provide the caregiver with valuable educational information about the disease as well as some effective strategies for caring for the Alzheimer's victim. Further, through its Alzheimer's support groups, this organization gives caregivers a chance to socialize with other similar individuals and provides an emotional outlet to vent frustrations, angers and anxieties.

A second organization of importance is the National Institute on Aging (NIA) which provides extensive information and publications about Alzheimer's disease which are useful tools for a caregiver. The third organization is the Administration on Aging (AoA) which has a network comprised of numerous branches designed to help caregivers access and utilize various services and programs.

The Alzheimer's caregiver must also be encouraged to consult medical professionals to receive helpful tips and treatments for their situation. Nurses can offer Alzheimer's caregivers helpful advice for the best way to care for their loved one. Some areas include medication monitoring and awareness, safety suggestions, useful activities, nutrition maintenance, exercise promotion and behavior modifications (Greenway \& Walker, 1998). It is also important for the caregiver to consult a physician to help manage the health problems they are personally experiencing. Physicians can help a caregiver with depression and sleep disorders as well as serve as an important and influential source of encouragement for the caregiver to take care of themselves and find time for stress relief (D’Epiro, 1998).

Caregivers should also be made aware of home health services and adult day centers to help ease some of the caregiver burden. There are various types of home care services to help with medical treatment, personal care, homemaking and companionship. 
Adult day centers usually accept patients between 4 and 12 hours per day (Burns et al, 1996). These resources could provide the caregiver with some personal time or allow the caregiver to continue their job.

Finally, caregivers need to be encouraged to schedule some time where they are away from the care recipient (Burns et al, 1996). Even a little bit of time spent relaxing or socializing with friends and other family members can be rejuvenating. This time gives the caregiver an outlet to compartmentalize their caregiving duties for a moment and just be free to enjoy being themselves.

\section{Summary}

Retrospective research has been used extensively to assess health, nutrition, behavior and activity. This type of research relies on the subject to recall relevant information that occurred prior to the interview. From this information, data can be analyzed and patterns identified which can lead to the development of successful intervention strategies (Beall \& Eckert, 1986).

This Alzheimer's caregiver study seeks to apply the retrospective technique of recall using a slightly different method. This study is interested in the recalling of past information by the caregiver in relation to their caregiver role and the period of time following its conclusion. This study diverges from the traditional retrospective research in that it asks more of the subject then just regurgitation of data. Rather, it asks that the subject deeply consider and ruminate the information being recalled as they convey it to the researcher. Because of this last significant twist on the traditional retrospective study, we have termed this a reflective study of Alzheimer's caregivers 


\section{Chapter 3}

\section{Methods}

One of the main goals of Alzheimer's research is to identify and disseminate ways to help caregivers cope with, manage and survive their situations. In keeping with this goal, this qualitative study seeks to obtain such information through interviews with the most knowledgeable sources possible, former Alzheimer's caregivers. The reflections shared by these individuals will serve as valuable assets to researchers and caregivers by providing unique insight into the Alzheimer's caregiver role and the transition period following its conclusion.

\section{Qualitative Methods}

For many years, the only research conducted in the aging field was quantitatively based. It is only in the last decade that a qualitative approach has become an acceptable methodology to use in gerontological studies (Rubinstein, 1994). Researchers have begun to see the usefulness of the unique information gathered in a qualitative study. They have also realized the important reciprocity that exists between the qualitative and quantitative approaches.

It would, however, be a great error to adopt a purely qualitatively-centric view of research. The benefits and necessity of quantitative research are numerous and cannot be overlooked or omitted. The best approach to adopt is one which considers the complimentary relationship that exists between the two methods and the potential joint areas of research development (Rubinstein, 1994). For example, although this is primarily a qualitative study, it will use as part of its instrumentation a survey technique to numerically identify intensity ratings of emotions at two separate states in the caregiver experience.

Qualitative methodology is important in this study because of its usefulness and applicability to research which explores factors and complexities which have not yet been 
identified (Marshall \& Rossman, 1989). The reflections of each subject will be unique and the information contained in them cannot be fully identified or estimated before the study.

The qualitative method, particularly the interview technique, is extremely important in this study because of the subject material being considered. The interview technique allows the researcher to obtain information that is of a high quality, in both substance and value, and also allows the researcher to obtain more in-depth information (Palmerino, 1999). The interview technique will produce more salient and personal information then can be extrapolated from a survey or telephone conversation. Sample

The subjects in this study were former Alzheimer's caregivers. For all of the subjects $(\mathrm{N}=20)$, their role as caregiver was terminated by the death of the care recipient. The time frame for this study included individuals up to seventeen years removed from the ending of their caregiver role. This sample population was obtained through personal contacts with the Alzheimer's Association Oklahoma Chapter and through Alzheimer's support groups

The majority of the respondents were between $55-65$ years of age (mean=63.9), predominantly female ( $80 \%$ ) and almost entirely white $(90 \%)$ (Table 1). The majority of the sample a high school degree or beyond $(80 \%)$ and were predominantly professionals $(60 \%)$. Forty percent of the respondents were caring for their husbands and an equal percentage were daughters caring for a parent. The duration of the caregiver role ranged mainly from 1-10 years, with the average span being 7 years. The majority of the respondents were between 1-5 years removed from their caregiver experience (mean $=4.8$ years).

Insert Table 1 
This was a convenience sample, chosen on the basis that the subject met the given criteria and was willing to participate in the study. Because every caregiver experience is unique, the results of this study cannot be generalized and assumed to be true of every Alzheimer's caregiver. Participation in this study was purely voluntary and the information reported from the interviews was done with respect to individual anonymity The researcher also provided each subject with a consent form documenting the existing confidentiality agreement.

Instrument

The instrument was designed to specifically explore information relevant to the reflections of Alzheimer's caregivers on their caregiving experiences and the time frame following their conclusion. It was constructed in such a way as to guide the subject from the beginning of the caregiver role through its conclusion and to the present time.

The instrument consisted of six parts (see Appendix A). The first two parts focused on obtaining background information for the researcher to build upon. The first part of the instrument identified demographic factors which were used in compiling a caregiver profile. The second part ascertained what event(s) initiated the adoption of the caregiver role for each subject.

The third section of the instrument involved the utilization of a semantic differential survey. This type of survey is constructed using terms which are directly opposite in meaning from each other (Osgood, 1957). The subjects are asked to rank where they fit on a given continuum in relation to each set of terms. For example, a set of terms could be happy and sad and the subject would indicate if they felt very sad, somewhat sad, neutral, somewhat happy or very happy in the situation of interest. The survey in this study consisted of several emotion/feeling terms, identified as being present in Alzheimer's caregiver situations. The subjects were asked to reflect back to their caregiver roles and rate the intensity of their feelings according to each term presented. (This survey was administered again at a later section in the interview) 
The fourth section of the interview focused on each subject's reflections throughout the caregiver experience. The researcher was particularly interested in identifying what each subject viewed as both successful and unsuccessful in their experience. The subjects were also asked to share any regrets they felt and discuss any barriers they encountered during their caregiver experience.

The fifth section focused on the transition period from the death of the care recipient to the time of the interview. The researcher asked questions designed to lead each subject chronologically through this transitionary time frame. The researcher also readministered the survey given in section III of the instrument. The same survey was given, however, the subjects were asked to base their answers on their current emotions and feelings.

To conclude the interview, the researcher asked each subject to give advice to current and future caregivers. This was an open-ended question, not focusing on any one section or time period of the caregiver experience. The advice given was at each subject's own discretion according to what they felt was most important.

\section{Limitations}

One limitation of this study stemmed from the use of a convenience sampling methodology. Because of this, the sample composition was largely homogenous with respect to ethnicity and gender. This factor limits the generalizability of the findings.

A second limitation concerned the difficulty the researcher had in obtaining the sample size. It was assumed that the majority of the sample would be obtained through referrals from other subjects. However, this type of subject identification only accounted for a very small percentage of the total sample. It is quite possible that the sensitivity of the study made subject acquisition difficult. 


\section{Chapter IV}

A Reflective Study of Alzheimer's Caregivers

MANUSCRIPT FOR PUBLICATION

Journal Title: Geriatrics 


\section{Introduction}

The demographic structure of America has traditionally taken the shape of a standard pyramid. The broad base of this pyramid has represented the population segment in its mid twenties and younger. The narrower apex of the pyramid has signified those individuals over the age of sixty-five (Blieszner \& Bedford, 1994). However, over the last decade, America has experienced a demographic transition which has altered this traditional depiction. This transition is a movement from a predominantly younger to a predominantly older population and is due to a combination of low fertility and low mortality rates (Attarian, 1999). If this transition continues, it is predicted that by the year 2025 , the traditional population pyramid will begin to invert, placing the over sixty-five group as the largest segment of the pyramid (Blieszner \& Bedford, 1994).

One of the major contributors to this demographic inversion is a significant increase in life expectancy over the last century. In 1900s America the average life expectancy was less than fifty years. By the 1950 s the life expectancy had increased to around seventy years of age. Today, the life expectancy for females is seventy-nine years and seventy-three years for males (Meier \& Morrison, 1999).

This increase in life expectancy has traditionally been cheered by a society whose main focus on aging has been the elongation of life. Recently the cheers have been muffled, however as society is forced to deal with the fact that with increased age there is also increased risk for disease and dependency. Although medical advances have been able to increase life expectancy, they have been unable to find the answers to many of the diseases which jeopardize the quality of life for those extended years. The current and projected demographic structure creates a heightened sense of urgency to solve these problems before society is faced with them in epidemic proportions.

One of the most prominent of the unsolved problems facing the elderly is Alzheimer's disease. Alzheimer's disease is the most common form of dementia in the elderly and is characterized pathologically by cerebral atrophy, neurofibrillary degeneration 
and senile plaques (Sloane, 1998). The onset of Alzheimer's disease occurs between the ages of forty and ninety, with the greatest risk coming after the age of sixty-five. In fact, for every 5 years beyond sixty-five, the risk of Alzheimer's disease doubles (Rose, 1999)

Alzheimer's disease is classified as a degenerative disease which manifests itself as random forgetfulness. This forgetfulness progresses to more severe memory loss which then leads to confusion, loss of speech and mobility, paranoia, hallucinations and behavioral problems (Khachaturian, 1997). In the end the victim is left completely helpless, trapped in a body that no longer functions, recognizes, or remembers.

The National Institute on Aging estimates that there are currently 4 million victims of Alzheimer's disease in America alone. It is projected that by the year 2050 this number could more than triple (Sikanovski, 1998). Because of the overwhelming nature of these figures, Alzheimer's disease has become one of the main areas of focus for aging researchers.

Alzheimer's research can be approached from a medical standpoint or from a social standpoint. The medical approach is focused on the causative, preventive and curative factors of the disease. It was estimated that the government spent over $\$ 350$ million in 1998 engaged in such research (Joyner, 1998). Although studies have reported optimistic findings based on genetic linkages, the cure for the disease remains elusive (Sikanovski, 1998).

The second approach to Alzheimer's research concerns the social aspects of the disease. Social researchers concerned with Alzheimer's disease place their focus on how to best care for the Alzheimer's victim (Sikanovski, 1998). The scope of their research extends beyond the direct victims themselves; to include the families and friends who often form the crucial supporting networks. It is these individuals who are often faced with the responsibility of caring for a loved one and must themselves struggle to survive the disease. A major component of such research is to explore the needs and experiences of 
these caregivers in an attempt to establish better ways of coping with and managing the progressively deteriorating stages of Alzheimer's disease.

\section{Caregiver Experience}

Estimates indicate that there are at least $\mathbf{4}$ million victims of Alzheimer's disease in America today (Sikanovski, 1998). Further estimates show that of these 4 million victims, over half will be cared for at home (Rose, 1999). The caregivers for these victims are family and friends who have chosen to alter their lives and take on the responsibility for their loved one's care. In a very real way, by adopting the role of the caregiver, these individuals also become victims of the disease, as they must struggle themselves to survive it.

The struggle these caregivers face is immense, trying both their mental and physical capabilities and exhausting their emotional reserves. Researchers have acknowledged the enormity of the caregiver burden and have focused their attention on finding better ways to cope with and manage the caregiver experience. Effective strategies, educational tools, support services and outreach organizations have been developed to help guide the caregiver from the beginning of the disease, through its three stages, and finally to their loved one's death and their own grief.

This cycle of support is crucial for Alzheimer's caregivers to successfully survive the disease. However, what happens to the caregiver once he or she is outside the cycle? The individual is still left with a variety of emotions, thoughts and memories which must be sorted out and come to terms with. During this renegotiation process, the individual will be continuously reflecting on their role as caregiver. The contents of these reflections are a valuable asset for other caregivers to learn from and use throughout their own experiences.

It is also important to recognize the significance of the transition period out of the caregiver role. Since the death of their loved one is an event that every caregiver will eventually face, it is important to explore the stages that follow this event This 
exploration will establish facts to help extend the cycle of support through the time when the caregiver must renegotiate their life and come to terms with the past.

\section{Theoretical Orientation}

The focus of this study centers around the reflections of Alzheimer's caregivers on their roles and experiences. This focus places the caregiver in the position of expert and assigns the researcher the tasks of listening and understanding. In order to attain this understanding, the researcher must put herself in the position of the caregivers in an attempt to visualize the reflections through their eyes. Through this transposition, the researcher can better create a frame of meaning for a caregiver's actions and behaviors, which will facilitate the understanding and analysis of each caregiver's reflection.

\section{Symbolic Interaction}

Symbolic interactionism will serve as the theoretical basis to guide the researcher in the formation of such meaning. From its beginning, symbolic interactionism has focused on exploring ways to understand different situations and behaviors (LaRossa \& Reitzes, 1993). This framework attempts to provide a method for researchers to understand how subjects define certain situations and how those definitions affect observed behaviors (LaRossa \& Reitzes, 1993). Symbolic interactionism will aid the researcher in first understanding the caregivers perspective to help understand the information conveyed by each caregiver.

\section{Assumptions}

This study will utilize two assumptions made by symbolic interactionism which are directly applicable to reflective caregiver research. First, to understand human behavior one must understand the meaning of the observed behavior to the actor (Klein \& White, 1996). The researcher must attempt to identify a frame of meaning for each caregiver in order to accurately analyze each reflection. This assumption also serves as an important guideline in alerting the researcher that each caregiver's frame of meaning will vary. 
Therefore, the information contained in each reflection must be differentiated according to that meaning.

The second assumption of relevance is that actors define a given situation and consequently define the problems which arise from the situation and the steps they take to solve those problems (Klein \& White, 1996). It is critical in this study to identify how each caregiver viewed their particular situation in order to better understand behaviors and actions during and after the caregiving experience. For example, if one caregiver views a situation as problematic, the ensuing behavior will differ from another caregiver who views the same situation less negatively. The researcher will need to be aware of such variations in order to avoid drawing erroneous conclusions from the caregivers' reflections.

Time Orientation

Finally, there are two time-oriented concepts from symbolic interactionism which are useful for reflective research. The first of these concepts is termed the symbolically reconstructed past. This refers to the time period where the actor renegotiates past stages and events in his or her life (Knipscheer, 1988). This concept serves as the basis of each caregiver's reflection. Each reflection is comprised of renegotiations of past experiences by the subjects to have current value and meaning in their present lives.

The second temporal concept is the social-structural past. This concept encompasses the notion that present and future behaviors and actions are governed by past events (Knipscheer, 1988). The impact of the caregiver experience on each subject will affect the transition period out of the caregiver role. The duration, actions and emotions of the stages will be impacted in various ways according to each caregiver's experience. The researcher must analyze the data to identify the impact of the caregiver experience on each of these elements.

The symbolic interactionist framework is a powerful force in research because it focuses on understanding behavior through the eyes of the actor instead of the observer 
In this study, the actors are former Alzheimer's caregivers who have been asked to recount both their experiences as caregivers and their experiences as they move out of the caregiver role. The researcher will utilize the theoretical basis of symbolic interactionism to analyze each reflection from the perspective of the caregiver. This method will allow the researcher to draw conclusions which are accurate and relevant to both the research and caregiver communities.

\section{Review of Literature}

\section{An Overview of Alzheimer's Disease}

\section{Demographics}

The National Institute on Aging estimates that there are currently 4 million victims of Alzheimer's disease in America alone (Sikanovski, 1998). The leading risk factor for this disease is old age, with a 1 in 3 chance of development after age eighty-five (Sloane, 1998). This statistic is significant because it is the eighty-five and older group that is the fastest growing population segment in the U.S. (Khachaturian, 1997). If this demographic trend continues and the disease maintains its present course, estimates indicate that the number of Alzheimer's victims in the US could more than triple to over 14 million by the year 2050 (Sikanovski, 1998).

Alzheimer's disease has placed an enormous financial burden on the US. It has been estimated that this disease costs the country $\$ 67.3$ billion annually (D’Epiro, 1998). This figure includes the care provided for Alzheimer's victims, the costs of medical and social research and the money American businesses lose from victims and caregivers who can no longer work (Joyner, 1998). Amazingly, this number is only projected to increase as care standards improve and the average duration of the disease is extended from eight years to as long as twenty years (Khachaturian, 1997). 


\section{History}

Alzheimer's disease was not identified as a distinct disease until the early 1900s (Khachaturian, 1997). In 1901, a fifty-one year old woman, Auguste D., was admitted into the Hospital for the Mentally Ill and Epileptics in Frankfurt, Germany (Enserink, 1998). The hospital's senior physician, Alois Alzheimer, examined Auguste and was amazed by her symptoms. Alzheimer reported that Auguste was disoriented; showed reduced levels of comprehension and memory; displayed erratic behavior; experienced paranoia and hallucinations and was suffering from pronounced psychosocial impairment (Maurer, Volk \& Gerbaldo, 1997).

In 1906, Auguste D. died and Dr. Alzheimer was given permission to autopsy her brain. In his results, Alzheimer documented finding substances which he referred to as "odd brain-tissue growths" (Khachaturian, 1997). He presented these results later that year at the 37th Conference of South-West German Psychiatrists in Tubingen, Germany. In 1910, Kraepelin, a German psychiatrist who had worked on the Auguste D. case, used the term "Alzheimer's disease" for the first time in a psychiatry handbook to describe Alzheimer's findings (Enserink, 1998).

\section{Pathology}

Since the documentation of the Auguste D. case, the pathology of Alzheimer's disease has attracted much scientific interest. This attention has led to the successful identification of two cardinal pathologic features found in the brain of every Alzheimer's victim. These two features are neuritic plaques and neurofibrillary tangles (Selkoe, 1997). Recent research has identified a third lesion, termed an AMY plaque, which may prove to be another identifying feature of Alzheimer's disease (Sikanovski, 1998).

The neuritic plaques, characteristic of Alzheimer's disease, are extracellular masses of beta-amyloid filaments. The other cardinal feature in the brain, neurofibrillary tangles are intracellular masses of altered protein (Selkoe, 1997). The principle component in these plaques is the beta-amyloid peptide. In the brains of normal individuals, beta- 
amyloid deposits are found sparingly. In contrast, in an Alzheimer's brain, there is an increase in production and deposition of this peptide (Jay, 1997).

The buildup of beta-amyloid peptides in the brain stimulates an inflammatory-like response by the tissue. This response causes neuronal injury which leads to synaptic loss and multiple neurotransmitter deficits. Scientists often use the analogy that beta-amyloid deposits are to Alzheimer's disease what cholesterol buildup is to heart disease (Selkoe, 1997).

\section{$\underline{\text { Diagnosis }}$}

The diagnostic process for Alzheimer's disease identification involves many multidimensional procedures. The physician must first obtain a detailed history of the patient's cognitive and behavioral changes, focusing on their progression over time (Geldmacher \& Whitehouse, 1996). This history should be collected from the patient as well as from a spouse or other close relative to receive the most accurate account possible.

The next phase in the diagnostic procedure involves a physical and mental examination of the patient. The physical exam is important to identify other factors which could be causing the patient to exhibit Alzheimer's-like symptoms. The mental examination usually utilizes the Folstein MiniMental State Examination (MMSE) to assess such factors as memory, orientation, motor skills and judgment. The results from this test do not rule out or confirm an Alzheimer's diagnosis. Instead, they serve as a significant tool to be used in conjunction with the other observations (Gonzalez, 1999).

After evaluating all of the test results together with a patient's history, a physician can make a possible, probable, or definite diagnosis of Alzheimer's disease (Gonzalez, 1999). In many cases, the diagnosis is not Alzheimer's disease, rather it is a curable condition such as malnutrition or depression. However, when Alzheimer's disease is indicated, the patients and their families can then take the steps needed to maximize quality of life. 


\section{Stages of Alzheimer's Disease}

Every individual affected by Alzheimer's disease will have their own unique experiences with the course of the disease. However, researchers have identified some common thematic changes typical of the disease course, which they have grouped into three stages following the progression of the disease (D'Epiro, 1998).

In the early stage of Alzheimer's disease the victim shows signs of memory loss and has difficulty performing complicated cognitive functions. By the middle stage of this disease the victim struggles with both written and spoken language performance (D'Epiro, 1998). The middle stage is further characterized by the repetitive asking of questions and the inability to express oneself appropriately in conversation (Gonzalez, 1999). As impairment worsens, victims begin losing the ability to care for themselves, neglecting even basic hygienic habits. During this stage the individual may also experience hallucinations and paranoia as well as problematic behaviors such as rummaging, wandering and pacing (Khachaturian, 1997).

In the late stage of Alzheimer's disease, the person has become severely impaired to where assistance is required with all of the basic needs. The memory is gone and the victim no longer recognizes family or friends. Eventually the person will lose auditory comprehension and any ability to speak (D'Epiro, 1998). The victim develops eating difficulties and becomes frail and highly susceptible to falls and other illnesses and injuries. Incontinence becomes a problem and the body's muscles and joints become rigid. Eventually, the body and mind completely shut down. Some typical "causes" of death for an Alzheimer's victim are aspiration pneumonia, bacterial infections, general debility, falls, and fractures (White, 1997). 
Alzheimer's Caregivers

\section{Caregiver Demographics}

Demographic statistics show that the average age of a care recipient is seventyseven and the average age of a caregiver is forty-six. Further data indicate that the vast majority ( $85 \%$ ) of caregivers are related to the recipient, with only $15 \%$ being someone outside the family (Ten-Kate, 1997). Focusing particularly on Alzheimer's care data, it is estimated that of the 4 million victims with this disease over half will be cared for at home by either a spouse or a child (Rose, 1999).

\section{Differentiating the Alzheimer's Caregiver}

Any form of caregiving is an exacting process, which taxes a person physically, emotionally, financially and spiritually. Although every caregiver situation is unique, researchers have identified some common problems faced by Alzheimer's caregivers as a whole. These problems differentiate the Alzheimer caregiver from other caregivers through prevalence and severity.

Perhaps the most significant problem faced by Alzheimer's caregivers is the lack of reciprocity that exists in their situation. In other forms of caregiving the care recipient can often attempt to reciprocate the care they receive through words and actions of gratitude, helpfulness, cooperation and support. In contrast, with Alzheimer's caregiving, by the middle and late stages of the disease when the care is the most intensive, the patient can often no longer express gratitude or helpfulness. Instead, the care recipient is often full of anger and resentment toward the caregiver and becomes belligerent, uncooperative and even violent (Burns, Eisdorfer, Gwyther, \& Sloane, 1996). This imbalance where the caregiver feels that all they do is give without receiving anything back, often leads to higher levels of anger, resentment and frustration in the Alzheimer's caregiver.

Another major problem faced by Alzheimer's caregivers is depression. Although depression is often present in any type of caregiver situation, research indicates that it is more predominant and severe in an individual caring for someone with Alzheimer's 
disease (Meshefejan, McCusker, Bellavance \& Baumgarten, 1998). Compounding this statistic is the fact that many severely depressed Alzheimer's caregivers deny their condition or refuse or overlook getting treatment (Gannon, 1994).

Research has also shown that sons and daughters who are both caregivers to a parent with Alzheimer's and employed report higher levels of emotional, physical and financial strain than do others in a similar situation who care for physically impaired parents (Clipp \& George, 1993; Starrels, Ingersoll-Dayton, Dowler \& Neal, 1997). Alzheimer's caregivers also give more indications that the caregiving process impacts their personal and professional lives to a more negative extent when compared with other caregivers (Scharlack, 1989; Starrels et al, 1997).

A final key distinguishing feature of the Alzheimer caregiver relates to personal health issues. The role of Alzheimer's caregiver has been linked with higher incidences of health problems than levels seen in other caregivers (Ostwald, Hepburn, Caron, Burns \& Mantell, 1999). Some very common health problems affecting an Alzheimer's caregiver include sleep disorders, anxiety, chronic fatigue, hypertension and cardiovascular disease (Burns et al, 1996). Many of these develop because the caregiver does not take any time for themselves to eat right, exercise, relax and rest. The Alzheimer's caregiver becomes so burdened down by their situation that they lose sight of their own importance. Because of this, it is unfortunately becoming more common to see the Alzheimer's caregiver become the first casualty of the disease.

\section{Caregiver Resources}

There is no resource that can serve as a cure-all for the problems faced by an Alzheimer's caregiver. However, there are various programs which have been designed to help ease the caregiver burden and/or allow the caregiver some temporary relief from their situation. It is vital to the physical, mental and emotional preservation and well-being of the caregiver that they are made aware of the resources available and are informed about the importance of their use. 
There are several major organizational resources which every Alzheimer's caregiver should be made aware of. The first, and perhaps most important, is the Alzheimer's Association. This organization is made up of over 200 chapters located throughout 50 states and has 2,000 Alzheimer's support groups (Robinson, 1998). The Alzheimer's Association can provide the caregiver with valuable educational information about the disease as well as some effective strategies for caring for the Alzheimer's victim. Further, through its Alzheimer's support groups, this organization gives caregivers a chance to socialize with other similar individuals and provides an emotional outlet to vent frustrations, angers and anxieties.

A second organization of importance is the National Institute on Aging (NIA) which provides extensive information and publications about Alzheimer's disease which are useful tools for a caregiver. The third organization is the Administration on Aging (AoA) which has a network comprised of numerous branches designed to help caregivers access and utilize various services and programs.

The Alzheimer's caregiver must also be encouraged to consult medical professionals to receive helpful tips and treatments for their situation. Nurses can offer Alzheimer's caregivers helpful advice for the best way to care for their loved one. Some areas include medication monitoring and awareness, safety suggestions, useful activities, nutrition maintenance, exercise promotion and behavior modifications (Greenway \& Walker, 1998). It is also important for the caregiver to consult a physician to help manage the health problems they are personally experiencing. Physicians can help a caregiver with depression and sleep disorders as well as serve as an important and influential source of encouragement for the caregiver to take care of themselves and find time for stress relief (D’Epiro, 1998).

Caregivers should also be made aware of home health services and adult day centers to help ease some of the caregiver burden. There are various types of home care services to help with medical treatment, personal care, homemaking and companionship 
Adult day centers usually accept patients between 4 and 12 hours per day (Bums et al, 1996). These resources could provide the caregiver with some personal time or allow the caregiver to continue their job.

Finally, caregivers need to be encouraged to schedule some time where they are away from the care recipient (Bums et al, 1996). Even a little bit of time spent relaxing or socializing with friends and other family members can be rejuvenating. This time gives the caregiver an outlet to compartmentalize their caregiving duties for a moment and just be free to enjoy being themselves.

\section{Summary}

Retrospective research has been used extensively to assess health, nutrition, behavior and activity. This type of research relies on the subject to recall relevant information that occurred prior to the interview. From this information, data can be analyzed and patterns identified which can lead to the development of successful intervention strategies (Beall \& Eckert, 1986).

This Alzheimer's caregiver study seeks to apply the retrospective technique of recall using a slightly different method. This study is interested in the recalling of past information by the caregiver in relation to their caregiver role and the period of time following its conclusion. This study diverges from the traditional retrospective research in that it asks more of the subject then just regurgitation of data. Rather, it asks that the subject deeply consider and ruminate the information being recalled as they convey it to the researcher. Because of this last significant twist on the traditional retrospective study, we have termed this a reflective study of Alzheimer's caregivers.

\section{Purpose of the Study}

The purpose of this study was to explore the issues faced by Alzheimer's caregivers some time after the death of the care recipient. The caregivers were asked to 
reflect on both their caregiving experience and the time frame following its conclusion. The information from these reflections was used to explore and identify the stages involved in the transition out of the caregiver role. The results of this study will serve as a valuable asset for caregivers at the beginning, middle and end of their caregiving experiences.

\section{Objectives}

This study was guided by the following objectives:

1.) To generate a caregiver profile from the background information collected from each caregiver.

2.) To identify and explore the factors which precipitated the beginning of the caregiver role for each caregiver.

3.) To record and analyze the reflections conveyed by each caregiver.

4.) To use the reflective information to identify the stages which comprise the transition out of the caregiver role.

\section{Methods}

One of the main goals of Alzheimer's research is to identify and disseminate ways to help caregivers cope with, manage and survive their situations. In keeping with this goal, this qualitative study seeks to obtain such information through interviews with the most knowledgeable sources possible, former Alzheimer's caregivers. The reflections shared by these individuals will serve as valuable assets to researchers and caregivers by providing unique insight into the Alzheimer's caregiver role and the transition period following its conclusion.

\section{Sample}

The subjects in this study were former Alzheimer's caregivers. For all of the subjects $(\mathrm{N}=20)$, their role as caregiver was terminated by the death of the care recipient. The time frame for this study included individuals up to seventeen years removed from the ending of their caregiver role. This sample population was obtained through personal 
contacts with the Alzheimer's Association Oklahoma Chapter and through Alzheimer's support groups.

The majority of the respondents were between 55-65 years of age (mean=63.9), predominantly female ( $80 \%)$ and almost entirely white $(90 \%)$ (Table 1). The majority of the sample had a high school degree or beyond $(80 \%)$ and were predominantly professionals (60\%). Forty percent of the respondents were caring for their husbands and an equal percentage were daughters caring for a parent. The duration of the caregiver role ranged mainly from 1-10 years, with the average span being 7 years. The majority of the respondents were between 1-5 years removed from their caregiver experience (mean=4.8 years).

\section{Insert Table 1}

This was a convenience sample, chosen on the basis that the subject met the given criteria and was willing to participate in the study. Because every caregiver experience is unique, the results of this study cannot be generalized and assumed to be true of every Alzheimer's caregiver. Participation in this study was purely voluntary and the information reported from the interviews was done with respect to individual anonymity. The researcher also provided each subject with a consent form documenting the existing confidentiality agreement.

\section{Instrument}

The instrument was designed to specifically explore information relevant to the reflections of Alzheimer's caregivers on their caregiving experiences and the time frame following their conclusion. It was constructed in such a way as to guide the subject from the beginning of the caregiver role through its conclusion and to the present time. 
The instrument consisted of six parts (see Appendix A). The first two parts focused on obtaining background information for the researcher to build upon. The first part of the instrument identified demographic factors which were used in compiling a caregiver profile. The second part ascertained what event(s) initiated the adoption of the caregiver role for each subject.

The third section of the instrument involved the utilization of a semantic differential survey. This type of survey is constructed using bi-polar terms which are directly opposite in meaning from each other (Osgood, 1957). The subjects are asked to rank where they fit on a given continuum in relation to each set of terms. For example, a set of terms could be happy and sad and the subject would indicate if they felt very sad, somewhat sad, neutral, somewhat happy or very happy in the situation of interest. The survey in this study consisted of several emotion/feeling terms, identified as being present in Alzheimer's caregiver situations. The subjects were asked to reflect back to their caregiver roles and rate the intensity of their feelings according to each term presented. (This survey was administered again at a later section in the interview).

The fourth section of the interview focused on each subject's reflections throughout the caregiver experience. The researcher was particularly interested in identifying what each subject viewed as both successful and unsuccessful in their experience. The subjects were also asked to share any regrets they felt and discuss any barriers they encountered during their caregiver experience

The fifth section focused on the transition period from the death of the care recipient to the time of the interview. The researcher asked questions designed to lead each subject chronologically through this transitionary time frame. The researcher also readministered the survey given in section III of the instrument. The same survey was given, however, the subjects were asked to base their answers on their current emotions and feelings. 
To conclude the interview, the researcher asked each subject to give advice to current and future caregivers. This was an open-ended question, not focusing on any one section or time period of the caregiver experience. The advice given was at each subject's own discretion according to what they felt was most important.

\section{Limitations}

One limitation of this study stemmed from the use of a convenience sampling methodology. Because of this, the sample composition was largely homogenous with respect to ethnicity and gender. This factor limits the generalizability of the findings.

A second limitation concerned the difficulty the researcher had in obtaining the sample size. It was assumed that the majority of the sample would be obtained through referrals from other subjects. However, this type of subject identification only accounted for a very small percentage of the total sample. It is quite possible that the sensitivity of the study made subject acquisition difficult.

\section{Results}

\section{Precipitating Caregiver Events}

Respondents were asked to remember the event(s) which precipitated their adoption of the caregiver role. Fifty five percent of the respondents were able to pinpoint a specific event which they credited as leading directly to becoming a caregiver. The remaining $45 \%$ of the participants indicated that more generic changes over time led to the gradual adoption of caregiver responsibilities.

Of those who could remember a specific event, $36 \%$ indicated the event was the death of a previous caregiver, necessitating them filling the vacancy. For the rest, their events took the form of narratives or episodes after which they could not remember not being a caregiver. For example, one man who had cared for his wife recounted,

"I wanted to go and visit our son one Saturday morning. On our way we stopped to get coffee and rolls at the McDonald's, like we had for the last 15 years. She didn't 
remember the McDonald's and all of a sudden she didn't know where she was. It was like someone had turned off an electrical switch on her. From that time on it was downhill."

For the $45 \%$ who could not pinpoint a specific event, there was an accumulation of changes over time which led to their becoming caregivers. They noticed that bills went unpaid, usually clean houses were dirty, personalities changed, increased forgetfulness and very unusual behaviors. As one woman who cared for her husband said'

"It was a slow build-up.......can't say it was any one main event....I just knew something was slipping."

\section{Caregiver Reflections}

Successes. Respondents were asked to reflect back on their caregiver experiences and share any successes they had. Participants gave answers which fell into six main themes (Table 2).

Insert Table 2

The most common response given was that caregivers learned not to argue with the Alzheimer's victims, thereby diffusing potentially explosive situations. As one woman who cared for her husband shared,

"If it didn't make a difference let it go.... if the sky is green, it's green."

Respondents indicated that one of the greatest successes they had was using an adult day care center. This resource provided some respite from the constant demands of caregiving. As one man who cared for his wife commented,

"Using the day center allowed me some time to recharge my batteries."

Another point of success involved researching Alzheimer's disease and learning about its' typical manifestation and progression. Caregivers felt that researching the disease made them better prepared to deal with their loved one's behavior through the 
various stages of the disease. They felt they had a better understanding of what their loved one was going through and what they could expect in the future.

Failures. Respondents were asked to identify any failures they felt in their caregiver experience. Seventy percent of the respondents reported that they either did not have any, did not know or could not remember. A common response given is exemplified by this quote from a woman who had cared for her husband,

"....you try to forget the bad things and remember only the good things."

A small percentage of the sample (30\%) did specify some areas that failed to work. These included: using commands instead of requests, losing patience, trying to get other people to stay with the person and trying to force the person to do things they did not want to do.

Regrets. Respondents were asked to share some of the regrets they have/had concerning their experiences as caregivers. Seventy percent of the sample gave responses which fell into four main categories (Table 3). The remainder reported having no regrets after reflecting back on their experiences. As one woman who had cared for her husband said,

“...I did a lot of things wrong, but I did what I could... so I have no regrets."

\section{Insert Table 3}

For those respondents who had regrets, a common one was not getting help sooner. Respondents said that at the time they felt they were not doing enough, but on reflecting back they realized they had done too much and their own healths' had suffered This point is illustrated by the comment from a woman who had cared for her husband,

"I didn't get help right away and that ruined my health....just now, after almost four years am I beginning to feel like a person again." 
Another regret was a lack of patience and understanding toward their loved one. Caregivers reported feeling so overwhelmed at times that they lost their patience or became irate with the Alzheimer's victim. Caregivers also reflected back to the beginning of the disease and regretted not being very understanding because they did not know what was wrong or did not know enough about the disease to realize certain "erratic" behavior was common in Alzheimer's victims. As one wife said,

'I was mad at my husband for many years...... I finally realized he didn't do things on purpose."

The most common regret was having to use a nursing home at the final stages of the disease. Respondents reported, often in the same sentence, not wanting to use a nursing home, having to use a nursing home because there was nothing else they could do and regretting using a nursing home because they "shouldn't have." They also reported the decision to use a nursing home as being the hardest choice they ever had to make. As one daughter who had cared for her mother said,

"The hardest thing you ever have to do is put a parent in a nursing home .... but it's all you can do..."

Another revealing quote came from a woman who cared for her husband,

"It became impossible for me to keep him at home and I had to use a nursing home....it will always be the hardest thing I ever did...I shouldn't have...I had to."

One final regret that was mentioned was not telling the person they had the disease. The regret came as individuals remembered their loved ones saying that other people thought they were crazy or they felt something was wrong with their mind. Respondents felt that by not telling the victim they had limited the amount of autonomy the person could have had at the end of their life.

Barriers. Respondents were asked to share any barriers they encountered in their caregiver experiences. One percent of the sample reported that their experiences were 
barrier free. The majority of subjects mentioned barriers which fell into six main categories (Table 4).

Insert Table 4

One barrier mentioned occurred at the final stages of the disease when the caregiver had to utilize a nursing home. Respondents felt that the care and facilities for their loved ones were substantially below acceptable. Caregivers indicated that even after placing their loved one in the nursing home, they had to care for them on an almost 24hour basis to ensure they received proper care. Now the caregivers were being drained financially without any kind of physical/mental respite in return. As one woman who cared for her mother said,

"The nurses were hardly ever around and the aides didn't seem to care. The nurses never briefed the aides when they came on duty so they didn't know what to do or what to watch for."

A second barrier centered around accessing outside help. Respondents indicated that it was very frustrating not knowing what was supposed to be done. It was also very hard not knowing the proper steps to take to get help and not knowing who to talk to. This barrier was twofold, because once resources were located, caregivers then had to surmount the barrier of actually asking for help. As one man who cared for his mom said,

"We like to think we can do it by ourselves...I felt it was my responsibility... have to learn how to ask for help."

A third barrier concerned the stigma attached to Alzheimer's disease. For many respondents they began their caregiver experiences over ten years ago when Alzheimer's disease was not high profile. Caregivers shared their recollections of their loved ones not wanting anyone to know about their condition because they were afraid to be stigmatized as crazy and put in an institution. Because of this fear and the stigma attached to the 
disease, many caregivers were not able to access any type of support or talk to others about their experiences for many years.

The financial strain involved with the disease was another commonly cited barrier. Respondents indicated that financial concerns were a constant source of mental worry. Many respondents said that because they were middle class economically, they could not qualify for much of the aid that was available. For many there was the reality that they could afford care if their loved one lived for a few years, but were uncertain what would happen if the disease was prolonged. As one woman who cared for her mother said,

'We were middle of the road financially so we didn't qualify for assistance. I know we had money if mom lived for 1 to 2 years but if she lived for 20 ... it was a big worry and a burden."

Another barrier concerned the juggling of responsibilities and the conflicts that arose from the caregiver holding roles simultaneously which should in reality be exclusive. Many caregivers felt torn between the Alzheimer's victim and their own families. As one woman who cared for her mom said,

"I was torn between trying to take care of mom and trying to be a good wife and mother."

A final barrier involved the lack of support from other family members and friends. Respondents indicated that family members and friends who lived further away or who were not frequently around the person with Alzheimer's did not feel anything was wrong or that it really wasn't as severe as the caregiver made it out to be. Some family members refused to believe the Alzheimer's diagnosis even after the death of the victim. In some cases, the unbelief and doubt turned to criticism of the caregiver, further adding to the emotional burden of this role. As one woman who cared for her mother recounted, “...they said we were what was wrong with mom and that we were just taking away her independence." 
Respondents also mentioned that as the disease progressed friends began excluding them and often deserted them. Caregivers said that their friends did not know how to act around the person with Alzheimer's and felt uncomfortable and awkward. As one woman who cared for her husband explained,

'People feel ashamed ...but you can't help who gets it...it's like AIDS, people don't want to associate with you...it's not catching."

\section{Caregiver Transition}

Coping Mechanisms. Respondents were asked how they coped with the death of their loved one. The majority of respondents indicated that it was less difficult to deal with because of the feeling that they had lost their loved one already. The actual death was only a formality and a closure. The respondents own words best illustrate this point. One woman who cared for her husband stated,

"... he died a long time before he was buried."

Another wife emphasized the gradual loss felt with the deterioration of her husband,

"Each time he lost an ability you go through a grief... so when he died I was pretty much through my grief...I grieved 5 to 6 years before his actual death." Another daughter who cared for her mother shared,

“...I I started grieving years ago when mother didn't recognize us...that's when I lost my mother... when she physically died I felt like I lost my baby."

For some respondents coping with the actual death was hard. Many indicated they changed the house around and got rid of personal affects to erase the memories. Others coped with the death by keeping busy so they would not have the time to dwell upon it

Many respondents, however felt relief when the death of the victim came. For the majority this relief was tied to a religious belief or to a realization that their loved one was no longer suffering. As one wife stated,

"I felt relieved because I knew he was truly resting..." Another daughter shared, 
“..this was not what mom wanted or how she wanted to live... heaven's a reality... why would you want anyone to live here especially with Alzheimer's..selfish sorrow."

Still another daughter said,

"She was so sick for so long ....it was a relief because she wasn't suffering."

For many of these respondents, coping with death occurred by celebrating the life of the person. As one daughter who cared for her mother said,

"We went to the cemetery and then we went back to the church and had a celebration remembering her life."

Another daughter shared,

"It helped me to go back and look at pictures and reflect back and remember who she was throughout life."

Another daughter said,

"Mom was gone but for just a shell... after her death it was like momma was back...now that it was over... all the beautiful memories of her floated to the top."

Issues Following Death. Respondents were asked to share the major issues they had to deal with following the death of their loved one. Twenty five percent of the sample indicated they did not have any major issues after their loved one's death. The remaining $75 \%$ gave responses which fell into six main categories (Table 5).

Insert Table 5

Respondents indicated that they found themselves maintaining some of the same patterns they had as caregivers. For example, one woman who had cared for her husband said that as a caregiver she would get up about three times a night at certain times to check on everything. For a period after his death, she would continue to get up at those same times and could not sleep through the night. 
One issue that respondents who cared for their husbands indicated having to deal with was learning how to do certain things (banking, repair work, general maintenance, etc.) on their own. These women had been accustomed to their husbands being the providers and taking care of the business and maintenance aspects of the family. Now they found themselves in their later years having to learn these skills for the first time. As one woman said,

"I had to learn the hard way...I had to figure out how to do things by myself...young women today are more self sufficient...I depended on him so."

Another issue that arose was loneliness. Although respondents acknowledged that they felt the person's spirit had been gone a long time before their death, now that they were physically gone there was a loneliness. Respondents indicated that even when the person could not talk or comprehend they could still hold their hand, or read to them or hug them. After their death they realized they could no longer do those things. As one wife said,

“...even with Alzheimer's I still had him...."

Another issue that caregivers faced was dealing with the memories. For many it was initially painful to remember but then they began to divert their focus from the negatives to the positives of their loved one's life. Respondents indicated that it helped the healing process to remember their loved one before the disease and to rediscover who they were.

Respondents also had to deal with the issue of guilt. This guilt stemmed from two main sources. The first was a guilt derived from feelings of relief because it was all over. The second was a guilt over things they did or did not do as a caregiver.

A final issue was shared by those caregivers who had used a nursing home at the end of the disease. These respondents reported being unable to go back into a nursing home after their loved one's death. For some this stemmed from the anger they had towards the whole nursing home system. For others the smell and environment suddenly 
became too much to handle. Still for others, there was the issue of the painful memories that the facility rekindled.

Sources of Support. Respondents were asked to share who/what helped them get through their loved ones deaths. The sample generated several sources of support which fell into five main categories (Table 6).

\section{Insert Table 6}

Sixty percent of the sample turned to family and friends for support. Over half of the sample indicated that their faith and/or their church were major sources of support. A few of the respondents (15\%) turned to formal support services such as social workers and support groups. A final source of support mentioned by $15 \%$ of the sample was coworkers and employers. As one woman who had cared for her mother said,

“....they gave me the freedom to do what I needed.... if I needed to leave they understood that."

Current Issues. Respondents were asked to share some of the issues they were currently dealing with regarding their caregiver experience. Only $35 \%$ of the sample indicated that they had resolved all of their issues. For the remainder of the sample the issues being dealt with fell into five main themes (Table 7).

\section{Insert Table 7}

Some of the respondents were still dealing with anger issues. The impetus of this anger was best expressed by a woman who had cared for her husband,

"He was such a good man and had such a good heart.... why with all the bad people out there did it have to be someone who wanted to help others and society?" 
Forty percent of the respondents reported that they still missed their loved one greatly. Even though they tried to put the experience behind them and move forward with their lives, they were bothered by the deep feelings of longing they still had for the person. As one woman who had cared for her husband said,

"I still miss that boost from him to say everything was okay... he believed in me...I miss him so."

Respondents also said that they still found themselves reliving memories of their experiences. For some these memories brought back feelings of guilt and pain. As one woman who had cared for her father shared,

"I'm sad in my heart because I wasn't more compassionate, patient and understanding." Another woman who cared for her mother said,

"I dream about her still and it overwhelms me.....sheer sadness at the devastation of her life."

For others the memories were sources of happiness and comfort. As one man who had cared for his grandfather said,

"We still share some of the funny things he did....they were just unbelievable."

Respondents who were more recently removed from their caregiver experience indicated they were still having trouble regaining an identity apart from caregiver. One woman who had cared for her husband said,

'When you're a caregiver you're always so busy but when you're alone it's hard living everyday things."

Another woman who had cared for her mother said,

'T lost touch with who I am... don't know what I'm supposed to be doing now that I'm not a caregiver... still searching." 


\section{Perceptions of the Caregiver Experience}

Perceptions During Experience. Respondents were presented with two bi-polar terms and were asked to rank themselves on a continuum between these terms based on their feelings during the caregiver experience. The results (Table 8) show that the majority of respondents placed themselves on the negative side of the continuum. This was most evident for feelings of inadequacy, stress and burden.

Insert Table 8

Current Perceptions. Respondents were presented with the same list of terms but were now asked to answer based on their current feelings. The results showed that respondents now felt more positive, with the majority ranking themselves at the extreme positive end of the continuum (Table 9).

\section{Insert Table 9}

Comparison. Table 10 compares the sets of responses given by the participants. It is evident that more negative feelings during the caregiver experience were replaced by extremely positive feelings after the experience had ended.

Insert Table 10 


\section{Advice}

As a final question, respondents were asked what advice they would give to other Alzheimer's caregivers. Participants gave advice for the time when the individual was actually a caregiver and for the time following this period. The responses given were grouped into nine main categories (Table 11).

\section{Insert Table 11}

The most widely given piece of advice was to get help as soon as possible. The nature of this help would vary according to the situation and the caregiver involved. This point is best illustrated in the utilization of support groups. Some individuals highly recommended the use of support groups. One woman who cared for her husband said,

"It helps to know that others are in the same boat as you and you aren't alone... the group lets you talk things over and get things out of your system." In contrast, other individuals did not feel support groups were beneficial. As one woman who cared for her husband stated,

'I didn't use a support group because I didn't feel able to take on other people's problems on top of my own.....I didn't want to spend what little free time I had dealing with anything to do with the disease....it helped more to get completely away and think and do something else entirely disassociated from the disease."

Another commonly given piece of advice was that the caregiver should take care of themselves. Respondents acknowledged that this was hard to do but that it was 
imperative to allow for the best care of the Alzheimer's victim. As one daughter who had cared for her mom said,

'You must have patience... but patience only comes with eating right, exercising, taking care of yourself and getting out."

Other advice focusing on the caregiver experience included: researching the disease, thoroughly investigating potential nursing homes, getting a living will, keeping a journal/diary, keeping the person involved and letting the person do for themselves for as long as possible.

Respondents gave one main piece of advice for caregivers after the death of their loved one. The advice centered around giving back and helping others get through the disease. As one woman who cared for her mother advised,

'Now that you're through go back and help someone else like you were helped or like you wanted to be helped."

Participants thanked the researcher for taking an interest in their experiences and for recognizing the wealth of knowledge they had about the Alzheimer's experience and the great desire they had to share their information.

\section{Discussion}

\section{Caregiver/Researcher Perspectives}

Symbolic interaction posits that in order to truly understand a situation it must be considered from both an observer's perspective and the perspective of the actor involved in the situation. In this study the actors involved are former Alzheimer's caregivers and the situation of interest is their reflections on their caregiving experiences. In order to more thoroughly and accurately understand these reflections, their contents must be 
considered from both the researcher's observations and from how each caregiver defined the situation and conveyed their personal views.

In this study, the introspective views held by the respondents often differed from the observations made by the researcher. This was most apparent in the reflections involving successes, failures and regrets.

Participants were asked to reflect back and share some of the successes they had in their caregiver experiences. The responses given tended to minimize or overlook the successes. Many respondents would relate a substantial list of positive actions and events and then at the end negate their importance by saying, "really nothing was very successful." Other caregivers would answer that they did not have any successes in their experience. However, through the course of the interview they identified numerous factors which the researcher classified as successes.

From the researcher's perspective all of the participants were successful caregivers and did many things which were of benefit to the person for which they were caring. However, in the eyes of the caregiver they were not successful. It is postulated that the subjects did not view themselves as successful because of the current societal preoccupation with the medical model of care. This model implies that if the end result of a medical situation is not complete recovery, the parties involved have in some way failed. Because each subjects' experience ended with the death of their loved one, they had difficulty applying the term successful to their caregiver experience.

A similar discrepancy is visible in the responses to the questions involving failures and regrets. When caregivers were asked what failures they had during their caregiver experience, the responses were brief and without substance. However, when the 
respondents were asked about the regrets they had concerning the caregiver experience, the responses were more elongated and involved.

From the observer's perspective, much of what the caregivers related as regrets were in fact failures. However, it is thought that respondents felt if they listed failures they would be symbolically labeling themselves as failures. Although caregivers could not connect the word success to their experience they were not prepared to acknowledge failure either. The use of the term regret allowed caregivers to share the unsuccessful factors of the caregiver experience with the researcher, without having to confront these experiences as failures.

\section{Transition Stages}

After the caregiver experience is over, the individual begins the transition out of the caregiver role. This transition involves several stages and can be multidirectional, with each direction leading to a different result (Figure 1). The transitionary period after the caregiver experience must not be overlooked or dismissed as insignificant, because its negotiation directly affects the individual's ability to adapt to life after caregiving.

The death of the Alzheimer's victim marks the beginning of the transition from the caregiver role. The intensity and variety of the emotions and feelings accompanying this death will vary among caregivers. However, every caregiver will experience some degree of relief in the swell of emotions. It is this feeling of relief that marks the second stage of the transition. The derivation of this relief varies among individuals. For some there is relief that their caregiver role is over. For others there is relief that their loved one is no longer suffering. Still for others, the relief comes from the knowledge that they can now 
move on with their lives. These sources of relief are not mutually exclusive and it is probable that individuals will experience some degree of each.

The feelings of relief directly lead to the next stage in the transition termed the stage of "current guilt." Individuals feel guilty about the relief that their loved one's death has brought. These feelings of guilt lead individuals to question their love and commitment to the Alzheimer's victim and subsequently to question their whole caregiver experience.

This guilt-derived questioning leads to the reflection stage of the transition. During this stage the individual relives portions of the caregiver experience. This reflection is shadowed by constant self-questioning and self-doubt.

Up to this point the transition model has been linear in progression. The effects of the reflection on the individual will lead to the model's first branching. If the majority or entirety of the reflection is overcast by self-criticism, the individual will enter into the stage of "reflected guilt." If however the individual balances self-criticism with self-praise, he/she will progress into the stage of acceptance.

The stage of reflected guilt involves a preoccupation with things that went wrong in the caregiver experience, regrets and other negative components. As figure 1 shows, reflected guilt leads to a continuous circle involving anger, sorrow and longing. For the individual each emotion feeds off the other, entrapping them in a cycle of negativity and failure. Individuals entrapped in this cycle end up in a stage of unresolution, where they cannot find contentment and closure to their caregiver experience. These individuals are so preoccupied with reliving the past, that it consumes their present and future. As long 
as the individual remains in this cycle, they will not successfully complete the transition out of the caregiver role.

In contrast, for those individuals who are able to move into the stage of acceptance, they have come to terms with their experiences and find some degree of contentment with their actions. This acceptance is supported by feelings of peace and hope, either involving spiritual renewal or future expectations. These individuals are able to live in the present and project into the future, while maintaining a balance of the past. These individuals will reach the stage of closure, signifying the successful transition out of the caregiver role.

\section{Implications}

There are currently over two million Alzheimer's caregivers in America today. As Alzheimer's disease becomes more prevalent this number will steadily increase. This study has several implications for both research and practical use to better serve and understand the needs of this growing population.

\section{$\underline{\text { Research Implications }}$}

The more research that is done on a topic the better the entirety of the topic is understood. This understanding comes not only form the results a study generates but also from the implications it produces for future research. This study has produced four major areas for future study.

The first implication involves the size and composition of the sample. A larger more diverse sample is needed to determine if the findings from this study are generalizable to the larger population. Also, specific studies should be designed to focus on ethnicity and Alzheimer's caregiving. The small percentage of the sample which was 
not white had a different view of the caregiver experience and felt that it was part of life's course and should be dealt with accordingly. This viewpoint led to a more peaceful outlook of the caregiver experience and a better adjustment following its conclusion. Future studies should look at how different ethnic groups view caregiving and how these views positively or negatively impact the caregiver experience.

The second implication concerns the importance of using a qualitative methodology. The majority of the information gained from this study would not have been attainable using a purely quantitative instrument. This study allowed subjects to share their feelings, experiences and concerns in their own words and provide explanations for their existence. Future research should recognize the importance and utility of a qualitative methodology to elicit responses which are in depth and revealing.

The third implication from this study involves the impact of spirituality on the caregiver experience. For many caregivers their faith/spirituality was a major source of support throughout their experience and in the transition immediately following. A sense of spirituality was attributed with a more positive outlook, better coping skills and a more successful transition out of the caregiver role. Future studies should focus on the impact of spirituality on caregiving, both during and after the caregiver experience.

The final implication from this study concerns what the researchers termed the phenomenon of "stage reversal." As an individual matures they pass through various stages (terrible twos, giddy teens, young adulthood etc.). Each stage is characterized by certain behaviors. It is postulated that the degenerative nature of Alzheimer's disease impacts victims in such a way that they retrace their steps, going backwards through the various stages. During the course of the interviews, respondents indicated being able to 
see this degeneration and to identify what stage their loved one was in by their behaviors and verbiage. Future research should explore this dichotomy of natural growth and pathological deterioration to perhaps identify the stages which are most obvious and the accompanying behaviors in each stage.

\section{Applied Implications}

This study showed that caregivers have the need to access various support services both during and after their caregiver experience. However, this need will go unmet if caregivers are not aware of or cannot easily access these services. In addition, support service personnel need to recognize the barrier of actually asking for help that impedes many caregivers from seeking assistance.

This study showed that services particularly needed by caregivers include respite programs, support groups, financial and legal assistance, better nursing homes and situational advice. This study also showed the importance of former Alzheimer's caregivers staying involved and helping other caregivers through the disease. However, even if these services are provided they must be disseminated to the caregiver population and must be easily accessible and convenient.

\section{Conclusion}

Despite recent medical advances and discoveries, Alzheimer's disease will continue to have a major impact on society. This disease is doubly vicious because it not only steals the memories of its victims but it devastates the lives of those who care for them. It is becoming more common that the Alzheimer's caregiver is the first casualty of the disease This is often due to a lack of information and support available to the caregiver. 
This study recognized the importance of helping the Alzheimer's caregiver survive the disease. It also recognized that the most knowledgeable sources about a situation are those individuals who have already been through it. Therefore, the best way to help current and future caregivers is to talk with former Alzheimer's caregivers and find out about their experiences.

This study collected the reflections of former Alzheimer's caregivers concerning their experiences as caregivers and the time following the death of the Alzheimer's victim The results show that former Alzheimer's caregivers remember their experiences vividly and have a wealth of information and advice to share concerning them. Having already been through the situation, respondents could share about particular needs that were unmet and issues they faced in their experiences. It is imperative that service providers and researchers consider the contents of these reflections and realize the importance of their applicability to helping current and future Alzheimer's caregivers survive the disease 


\section{References}

Attarian, J. (1999). Demographic iceberg dead ahead. The World \& I, 14(6), 260-265.

Beall, C. \& Eckert, K. (1986). Measuring functional status cross-culturally. In C. Fry \& J. Keith, (Eds.). New Methods for Old Age Research. (pp. 21-44). South Hadley, Mass: Bergin \& Garvey.

Blieszner, R. \& Bedford, V. (1994). Aging and the Family. Westport: Praeger.

Burns, R., Eisdorfer, C., Gwyther, L., \& Sloane, P. (1996). Caring for the caregiver. Patient Care, 30(18), 108-130.

Clipp, E. \& George, L. (1993). Dementia and cancer: A comparison of spouse caregivers. The Gerontologist, 33, 534-541.

D'Epiro, N. (1998). Alzheimer's disease: Current progress, future promise. Patient Care, 32(9), 156-176.

Enserink, M. (1998). First Alzheimer's diagnosis confirmed. Science, 279(5359), 2037-2038.

Gannon, K. (1994). Alzheimer's takes toll on the 'hidden patient'. Drug Topics, $\underline{138}(8), 38-39$.

Geldmacher, D. \& Whitehouse, P. (1996). Evaluation of dementia. New England Journal of Medicine, 335(5), 197-211.

Gonzalez, J. (1999). How to assess memory loss in the elderly. Patient Care, $\underline{33}(5), 197-211$.

Greenway, M. \& Walker, A. (1998). Helping caregivers cope with Alzheimer's disease. Nursing, 28(2), 1-6.

Jay, G. (1997). Alzheimer's disease: From gene to pathology. The American Journal of Psychiatry, 154(10), 1359-1360.

Joyner, T. (1998). Cost of Alzheimer's mounts for companies. The Atlanta Constitution.

Khachaturian, Z. (1997). Plundered memories. Science, 37(4), 20-25 Sage.

Klein, D. \& White, J. (1996). Family Theories. (pp. 92-97). Thousand Oaks: 
Knipscheer, C. (1988). Temporal embeddedness and aging within the multigenerational family: The case of grandparenting. In J. Birren \& V. Bengtson, (Eds.). Emergent Theories of Aging. (pp. 426-441). New York: Springer.

LaRossa, R. \& Reitzes, D. (1993). Symbolic interactionism and family studies. In G. Boss, W. Doherty, R. LaRossa, W. Schumm \& S. Steinmetz, (Eds.). Sourcebook of Family Theories and Methods. (pp. 135-136). New York: Plenum.

Maurer, K., Volk, S. \& Gerbaldo, H. (1997). Auguste D and Alzheimer's disease The Lancet, 349(9064), 1546-1549.

Meier, D. \& Morrison, R. (1999). Old Age and care near the end of life Generations, 23(1), 6-11.

Meshefedjian, g., McCusker, J., Bellavance, F. \& Baumgarten, M. (1998). Factors associated with symptoms of depression among informal caregivers of demented elders in the community. The Gerontologist, 38(2), 247-253.

Osgood, C., Suci, G., \& Tannenbaum, P. (1957). The Measurement of Meaning. Urbana: University of Illinois Press.

Ostwald, S., Hepburn, K., Caron, W., Burns, T \& Mantell, R. (1999). Reducing caregiver burden: A randomized psychoeducational intervention for caregivers of persons with dementia. The Gerontologist, 39(3), 299-313.

Robinson, B. (1998). Resources for physicians and caregivers. Geriatrics, 53(1). 55.

Rose, V. (1999). Progress report on Alzheimer's disease. American Family Physician, 59(5), 1326.

Scharlach, A. (1998). A comparison of employed caregivers of cognitively impaired and physically impaired elderly persons. Research on Aging, 11, 225-243.

Selkoe, D. (1997). Alzheimer's disease: From genes to pathogenesis. The American Journal of Psychiatry, 154(9), 1198-1199.

Sikanovski, D. (1998). Alzheimer's disease: What we know now. Nursing Homes, 47(6), 56-57.

Sloane, P. (1998). Advances in the treatment of Alzheimer's disease American Family Physician, 58(7), 1577-1586.

Sloane, P. (1998). Information from your family doctor: When the diagnosis is Alzheimer's disease. American Family Physician, 58(7), 1589-1590. 
Starrels, M., Ingersoll-Dayton, B., Dowler, D. \& Neal, M. (1997). The stress of caring for a parent: Effects of the elder's impairment on an employed adult child. Journal of Marriage and the Family, 59(4), 860-872.

Ten-Kate, N. (1997). ...... and taking care. American Demographics, 19(9), 42

White, L. (1997). Alzheimer's disease: The evolution of a diagnosis. Public Health Reports, 112(6), 495-496. 


\section{Bibliography}

Attarian, J. (1999). Demographic iceberg dead ahead. The World \& I, 14(6), 260-265.

Beall, C. \& Eckert, K. (1986). Measuring functional status cross-culturally. In C. Fry \& J. Keith, (Eds.). New Methods for Old Age Research. (pp. 21-44). South Hadley. Mass: Bergin \& Garvey.

Blieszner, R. \& Bedford, V. (1994). Aging and the Family. Westport: Praeger

Brothwell, D. \& Sandison, A. (1967). Diseases in Antiquity. (pp. 717-718). Springfield: Bannerstone House.

Burns, R., Eisdorfer, C., Gwyther, L., \& Sloane, P. (1996). Caring for the caregiver. Patient Care, 30(18), 108-130.

Clipp, E. \& George, L. (1993). Dementia and cancer: A comparison of spouse caregivers. The Gerontologist, 33, 534-541.

D'Epiro, N. (1998). Alzheimer's disease: Current progress, future promise Patient Care, 32(9), 156-176.

Enserink, M. (1998). First Alzheimer's diagnosis confirmed. Science, 279(5359), 2037-2038.

Gannon, K. (1994). Alzheimer's takes toll on the 'hidden patient'. Drug Topics, $\underline{138}(8), 38-39$

Geldmacher, D. \& Whitehouse, P. (1996). Evaluation of dementia. New England Journal of Medicine, 335(5), 197-211.

Gonzalez, J. (1999). How to assess memory loss in the elderly. Patient Care, $\underline{33}(5), 197-211$.

Greenway, M. \& Walker, A. (1998). Helping caregivers cope with Alzheimer's disease. Nursing, 28(2), 1-6.

Jay, G. (1997). Alzheimer's disease: From gene to pathology. The American Journal of Psychiatry, 154(10), 1359-1360

Joyner, T. (1998). Cost of Alzheimer`s mounts for companies The Atlanta Constitution.

Khachaturian, Z. (1997). Plundered memories. Science, 37(4), 20-25 

Sage.

Klein, D. \& White, J. (1996). Family Theories. (pp. 92-97). Thousand Oaks:

Knipscheer, C. (1988). Temporal embeddedness and aging within the multigenerational family: The case of grandparenting. In J. Birren \& V. Bengtson, (Eds.) Emergent Theories of Aging. (pp. 426-441). New York: Springer.

LaRossa, R. \& Reitzes, D. (1993). Symbolic interactionism and family studies. In G. Boss, W. Doherty, R. LaRossa, W. Schumm \& S. Steinmetz, (Eds.). Sourcebook of Family Theories and Methods. (pp. 135-136). New York: Plenum.

Marshall, C. \& Rossman, G. (1989). Designing Qualitative Research. (pp. 7-44). Newbury Park: Sage.

Maurer, K., Volk, S. \& Gerbaldo, H. (1997). Auguste D and Alzheimer's disease. The Lancet, 349(9064), 1546-1549.

Meier, D. \& Morrison, R. (1999). Old Age and care near the end of life Generations, 23(1), 6-11.

Meshefedjian, g., McCusker, J., Bellavance, F. \& Baumgarten, M. (1998). Factors associated with symptoms of depression among informal caregivers of demented elders in the community. The Gerontologist, 38(2), 247-253.

Osgood, C., Suci, G., \& Tannenbaum, P. (1957). The Measurement of Meaning. Urbana: University of Illinois Press.

Ostwald, S., Hepburn, K., Caron, W., Burns, T. \& Mantell, R. (1999). Reducing caregiver burden: A randomized psychoeducational intervention for caregivers of persons with dementia. The Gerontologist, 39(3), 299-313.

Palmerino, M. (1999). Take a quality approach to qualitative research. Marketing News, 33(12), 35-36

Robinson, B. (1998). Resources for physicians and caregivers. Geriatrics, 53(1), 55 .

Rose, V. (1999). Progress report on Alzheimer's disease American Family Physician, 59(5), 1326.

Rubinstein, R. (1994). Proposal writing. In J Gubrium \& A Sankar, (Eds.) Qualitative Methods in Aging Research. (pp. 67-81). Thousand Oaks Sage

Sahelian, R. (1999). Huperzine A. Better Nutrition, 61(5), 26-27 
Scharlach, A. (1998). A comparison of employed caregivers of cognitively impaired and physically impaired elderly persons. Research on Aging, 11, 225-243.

Selkoe, D. (1997). Alzheimer's disease: From genes to pathogenesis. The American Journal of Psychiatry, 154(9), 1198-1199.

Sikanovski, D. (1998). Alzheimer's disease: What we know now. Nursing Homes, 47(6), 56-57.

Sloane, P. (1998). Advances in the treatment of Alzheimer's disease. American Family Physician, 58(7), 1577-1586.

Sloane, P. (1998). Information from your family doctor: When the diagnosis is Alzheimer's disease. American Family Physician, 58(7), 1589-1590.

Starrels, M., Ingersoll-Dayton, B., Dowler, D. \& Neal, M. (1997). The stress of caring for a parent: Effects of the elder's impairment on an employed adult child. Journal of Marriage and the Family, 59(4), 860-872.

Ten-Kate, N. (1997). ...... and taking care. American Demographics, 19(9), 42

White, L. (1997). Alzheimer's disease: The evolution of a diagnosis. Public Health Reports, 112(6), 495-496.

www.alz.org, 1999. 


\section{APPENDIXES}




\section{APPENDIX A}

Research Instrument 


\section{INSTRUMENT}

These are the questions that will be asked of each subject in the study:

I. Demographic Information

- How old are you?

- Gender?

$$
\text { _ Male __ Female }
$$

- What is your race?

- What is the highest level of education completed? Attended graduate or professional school Graduated from a four year college

Some college or technical school after high school

Finished high school

Some high school

Finished grade school/junior high

- What is/was your occupation?

- How were you related to the care recipient?

- How long did you serve as caregiver?

- How long has it been since the death of the care recipient?

II. What event precipitated your adoption of the caregiver role?

III. Semantic Differential Survey A - Targeting Beginning of Caregiver Role (App. B)

Question: Reflecting back to when you first became a caregiver, how would you rate your feelings during this time along the five point continuum for the following ten words?

IV. Caregiver Reflections:

1.) What were some of the successes you felt in your caregiver experience? 
2.) What were some areas of unsuccessfulness in your caregiver experience?

3.) What are/were some of the regrets you have/had concerning this experience?

4.) What were some barriers you encountered in your caregiving experience?

A. Probe questions:

Financial concerns

Family relationships

V. Transition Questions:

A.

1.) How did you cope with the death of the care recipient?

2.) What were the major issues you had to deal with following his/her death?

3.) What were your sources of support during this time?

4.) What are some major issues that you are currently dealing with?

B. Semantic Differential Survey B - Targeting Present Time 
Question: How would you currently rate your feelings regarding your past caregiver experience along the five point continuum for the following ten words?

VI. What is some advice you would give to other Alzheimer's caregivers? 


\section{SEMANTIC DIFFERENTIAL SURVEY A}

Instructions: Each participant will be given a copy of the survey and will be asked to indicate their position on the continuum between each set of terms. This survey will be administered at the beginning and ending of each interview.

Question: Reflecting back to when you first became a caregiver, how would you rate your feelings during this time along the five point continuum for the following ten words?

Very Some- Neutral Some- Very
Much what $\quad$ what Much

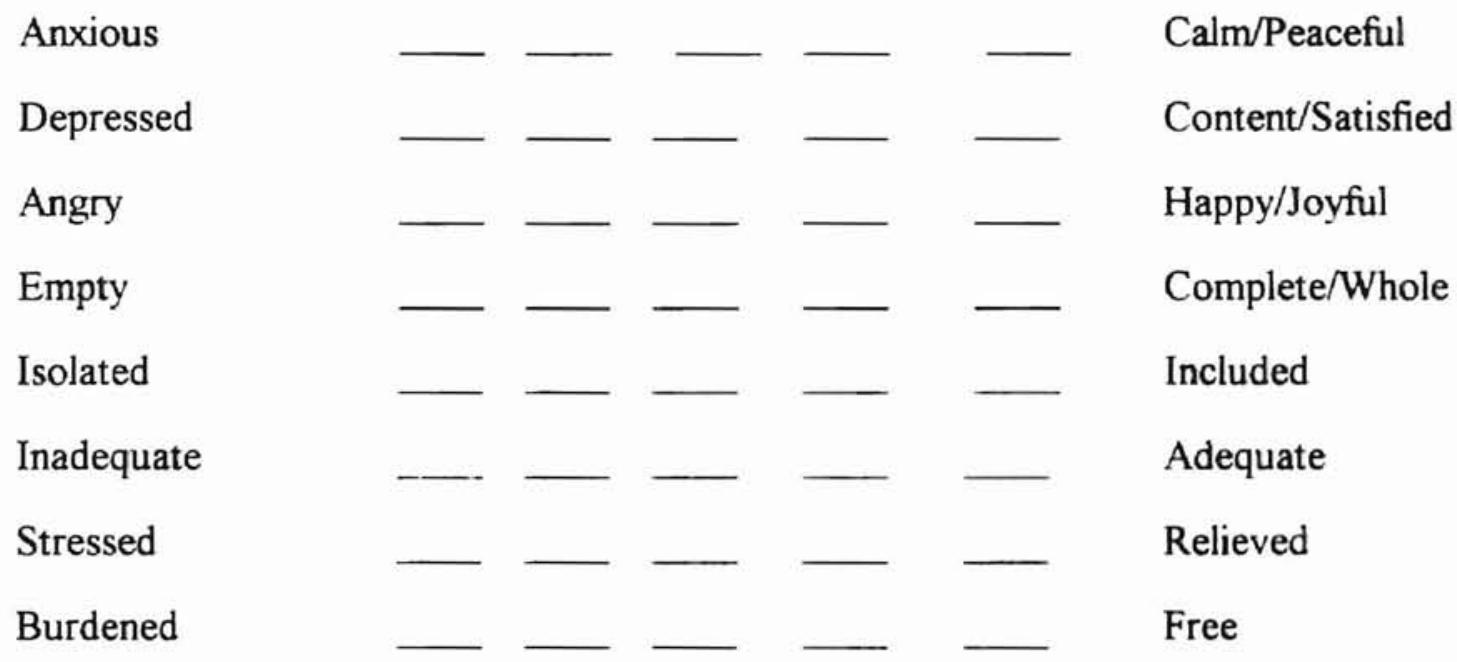




\section{SEMANTIC DIFFERENTIAL SURVEY B}

Instructions: Each participant will be given a copy of the survey and will be asked to indicate their position on the continuum between each set of terms. This survey will be administered at the beginning and ending of each interview.

Question: How would you currently rate your feelings regarding your past caregiver experience along the five point continuum for the following ten words?

$\begin{array}{lll}\text { Very Some- Neutral Some- Very } \\ \text { Much what } & \text { what Much }\end{array}$

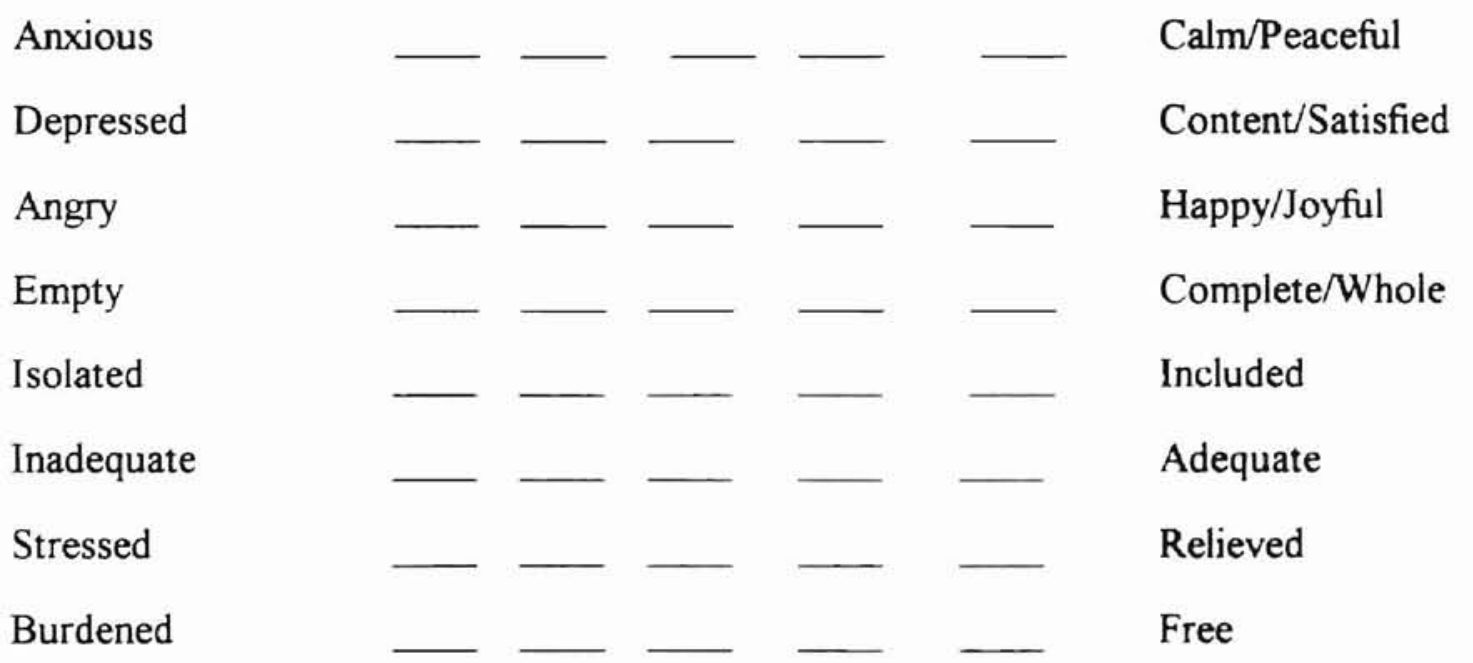




\section{APPENDIX B}

Analysis of Research Objectives and Tables 


\section{Research Objective One}

To generate a caregiver profile from the background information collected from each caregiver.

The subjects in this study were former Alzheimer's caregivers. For all of the subjects $(\mathrm{N}=20)$, their role as caregiver was terminated by the death of the care recipient. The time frame for this study included individuals up to seventeen years removed from the ending of their caregiver role. This sample population was obtained through personal contacts with the Alzheimer's Association Oklahoma Chapter and through Alzheimer's support groups.

The majority of the respondents were between $55-65$ years of age (mean=63.9), predominantly female ( $80 \%$ ) and almost entirely caucasian $(90 \%)$ (see Table 1). The majority of the sample had a high school degree or beyond ( $80 \%)$ and were predominantly professionals $(60 \%)$. Forty percent of the respondents were caring for their husbands and an equal percentage were daughters caring for a parent. The duration of the caregiver role ranged mainly from 1-10 years, with the average span being 7 years. The majority of the respondents were between $1-5$ years removed from their caregiver experience (mean $=4.8$ years). 


\section{Research Objective Two}

To identify and explore the factors which precipitated the beginning of the caregiver role for each caregiver.

Respondents were asked to remember the event(s) which precipitated their adoption of the caregiver role. Fifty five percent of the respondents were able to pinpoint a specific event which they credited as leading directly to becoming a caregiver. The remaining $45 \%$ of the participants indicated that more generic changes over time led to the gradual adoption of caregiver responsibilities.

Of those who could remember a specific event, $36 \%$ indicated the event was the death of a previous caregiver, necessitating them filling the vacancy. For the rest, their events took the form of narratives or episodes after which they could not remember not being a caregiver. For example, one man who had cared for his wife recounted,

"I wanted to go and visit our son one Saturday morning. On our way we stopped to get coffee and rolls at the McDonald's, like we had for the last 15 years. She didn't remember the McDonald's and all of a sudden she didn't know where she was. It was like someone had turned off an electrical switch on her. From that time on it was downhill."

For the $45 \%$ who could not pinpoint a specific event, there was an accumulation of changes over time which led to their becoming caregivers. They noticed that bills went unpaid, usually clean houses were dirty, personalities changed, increased forgetfulness and very unusual behaviors. As one woman who cared for her husband said,

"It was a slow build-up...... can't say it was any one main event ....I just knew something was slipping." 


\section{Research Objective Three}

To record and analyze the reflections conveyed by each caregiver.

Successes. Respondents were asked to reflect back on their caregiver experiences and share any successes they had. Participants gave answers which fell into six main themes (see Table 2).

The most common response given was that caregivers learned not to argue with the Alzheimer's victims, thereby diffusing potentially explosive situations. Respondents indicated that another success was using an adult day care center. This resource provided some respite from the constant demands of caregiving. Another point of success involved researching Alzheimer's disease and learning about its' typical manifestation and progression. Caregivers felt that researching the disease made them better prepared to deal with their loved one's behavior through the various stages of the disease

Failures. Respondents were asked to identify any failures they felt in their caregiver experience. Seventy percent of the respondents reported that they either did not have any, did not know or could not remember. A small percentage of the sample $(30 \%)$ did specify some areas that failed to work. These included: using commands instead of requests, losing patience, trying to get other people to stay with the person and trying to force the person to do things they did not want to do.

Regrets. Respondents were asked to share some of the regrets they have/had concerning their experiences as caregivers. Seventy percent of the sample gave responses which fell into four main categories (see Table 3). The remainder reported having no regrets after reflecting back on their experiences.

For those respondents who had regrets, a common one was not getting help sooner. Respondents said that at the time they felt they were not doing enough, but on reflecting back they realized they had done too much and their own healths' had suffered Another regret was a lack of patience and understanding toward their loved one. Caregivers reported feeling so overwhelmed at times that they lost their patience or 
became irate with the Alzheimer's victim. Caregivers also reflected back to the beginning of the disease and regretted not being very understanding because they did not know what was wrong or did not know enough about the disease to realize certain "erratic" behavior was common in Alzheimer's victims.

The most common regret was having to use a nursing home at the final stages of the disease. Respondents reported, often in the same sentence, not wanting to use a nursing home, having to use a nursing home because there was nothing else they could do and regretting using a nursing home because they "shouldn't have." They also reported the decision to use a nursing home as being the hardest choice they ever had to make.

One final regret that was mentioned was not telling the person they had the disease. The regret came as individuals remembered their loved ones saying that other people thought they were crazy or they felt something was wrong with their mind. Respondents felt that by not telling the victim they had limited the amount of autonomy the person could have had at the end of their life.

Barriers. Respondents were asked to share any barriers they encountered in their caregiver experiences. Less than $1 \%$ of the sample reported that their experiences were barrier free. The majority of subjects mentioned barriers which fell into six main categories (see Table 4).

One barrier mentioned occurred at the final stages of the disease when the caregiver had to utilize a nursing home. Respondents felt that the care and facilities for their loved ones were substantially below acceptable. Caregivers indicated that even after placing their loved one in the nursing home, they had to care for them on an almost 24hour basis to ensure they received proper care.

A second barrier centered around accessing outside help. Respondents indicated that it was very frustrating not knowing what was supposed to be done. It was also very hard not knowing the proper steps to take to get help and not knowing who to talk to. 
This barrier was twofold, because once resources were located, caregivers then had to surmount the barrier of actually asking for help.

A third barrier concerned the stigma attached to Alzheimer's disease. For many respondents they began their caregiver experiences over ten years ago when Alzheimer's disease was not high profile. Caregivers shared their recollections of their loved ones not wanting anyone to know about their condition because they were afraid to be stigmatized as crazy and put in an institution. Because of this fear and the stigma attached to the disease, many caregivers were not able to access any type of support or talk to others about their experiences for many years.

The financial strain involved with the disease was another commonly cited barrier. Respondents indicated that financial concerns were a constant source of mental worry. Many respondents said that because they were middle class economically, they could not qualify for much of the aid that was available. For many there was the reality that they could afford care if their loved one lived for a few years, but were uncertain what would happen if the disease was prolonged.

Another barrier concerned the juggling of responsibilities and the conflicts that arose from the caregiver holding roles simultaneously which should in reality be exclusive Many caregivers felt torn between the Alzheimer's victim and their own families.

A final barrier involved the lack of support from other family members and friends. Respondents indicated that family members and friends who lived further away or who were not frequently around the person with Alzheimer's did not feel anything was wrong or that it really wasn't as severe as the caregiver made it out to be. Some family members refused to believe the Alzheimer's diagnosis even after the death of the victim. In some cases, the unbelief and doubt turned to criticism of the caregiver, further adding to the emotional burden of this role. Respondents also mentioned that as the disease progressed friends began excluding them and often deserted them. Caregivers said that their friends 
did not know how to act around the person with Alzheimer's and felt uncomfortable and awkward.

Coping Mechanisms. Respondents were asked how they coped with the death of their loved one. The majority of respondents indicated that it was less difficult to deal with because of the feeling that they had lost their loved one already. The actual death was only a formality and a closure.

However, for some respondents coping with the actual death was hard. Many indicated they changed the house around and got rid of personal affects to erase the memories. Others coped with the death by keeping busy so they would not have the time to dwell upon it.

Issues. Respondents were asked to share the major issues they had to deal with following the death of their loved one. Twenty five percent of the sample indicated they did not have any major issues after their loved one's death. The remaining $75 \%$ gave responses which fell into six main categories (see Table 5).

Respondents indicated that they found themselves maintaining some of the same patterns they had as caregivers. For example, one woman who had cared for her husband said that as a caregiver she would get up about three times a night at certain times to check on everything. For a period after his death, she would continue to get up at those same times and could not sleep through the night.

One issue that respondents who cared for their husbands indicated having to deal with was learning how to do certain things (banking, repair work, general maintenance, etc.) on their own. These women had been accustomed to their husbands being the providers and taking care of the business and maintenance aspects of the family. Now they found themselves in their later years having to learn these skills for the first time Another issue that arose was loneliness. Although respondents acknowledged that they felt the person's spirit had been gone a long time before their death, now that they were physically gone there was a loneliness. Respondents indicated that even when the 
person could not talk or comprehend they could still hold their hand, or read to them or hug them. After their death they realized they could no longer do those things.

Another issue that caregivers faced was dealing with the memories. For many it was initially painful to remember but then they began to divert their focus from the negatives to the positives of their loved one's life. Respondents indicated that it helped the healing process to remember their loved one before the disease and to rediscover who they were.

Respondents also had to deal with the issue of guilt. This guilt stemmed from two main sources. The first was a guilt derived from feelings of relief because it was all over. The second was a guilt over things they did or did not do as a caregiver.

A final issue was shared by those caregivers who had used a nursing home at the end of the disease. These respondents reported being unable to go back into a nursing home after their loved one's death. For some this stemmed from the anger they had towards the whole nursing home system. For others the smell and environment suddenly became too much to handle. Still for others, there was the issue of the painful memories that the facility rekindled.

Sources of Support. Respondents were asked to share who/what helped them get through their loved ones deaths. The sample generated several sources of support which fell into five main categories (see Table 6).

Sixty percent of the sample turned to family and friends for support. Over half of the sample indicated that their faith and/or their church were major sources of support. A few of the respondents (15\%) turned to formal support services such as social workers and support groups. A final source of support mentioned by $15 \%$ of the sample was coworkers and employers.

Current Issues. Respondents were asked to share some of the issues they were currently dealing with regarding their caregiver experience. Only $35 \%$ of the sample 
indicated that they had resolved all of their issues. For the remainder of the sample the issues being dealt with fell into five main themes.(see Table 7)

Some of the respondents were still dealing with anger issues. Forty percent of the respondents reported that they still missed their loved one greatly. Respondents also said that they still found themselves reliving memories of their experiences. For some these memories brought back feelings of guilt and pain. For others the memories were sources of happiness and comfort. Finally, respondents who were more recently removed from their caregiver experience indicated they were still having trouble regaining an identity apart from caregiver.

Perceptions During Experience. Respondents were presented with two terms which were direct opposites of each other. They were asked to rank themselves on a continuum between these terms based on their feelings during the caregiver experience The results (see Table 8) show that the majority of respondents placed themselves on the negative side of the continuum. This was most evident for feelings of inadequacy, stress and burden.

Current Perceptions. Respondents were presented with the same list of terms but were now asked to answer based on their current feelings. The results showed that respondents now felt more positive, with the majority ranking themselves at the extreme positive end of the continuum (see Table 9)

Comparison. Table 10 compares the sets of responses given by the participants. It is evident that more negative feelings during the caregiver experience were replaced by extremely positive feelings after the experience had ended. 
Advice. Respondents were asked what advice they would give to other Alzheimer's caregivers. Participants gave advice for the time when the individual was actually a caregiver and for the time following this period. The responses given were grouped into nine main categories (see Table 11).

The most widely given piece of advice was to get help as soon as possible. The nature of this help would vary according to the situation and the caregiver involved. Another commonly given piece of advice was that the caregiver should take care of themselves. Respondents acknowledged that this was hard to do but that it was imperative to allow for the best care of the Alzheimer's victim.

Other advice focusing on the caregiver experience included: researching the disease, thoroughly investigating potential nursing homes, getting a living will, keeping a journal/diary, keeping the person involved and letting the person do for themselves for as long as possible.

Respondents gave one main piece of advice for caregivers after the death of their loved one. The advice centered around giving back and helping others get through the disease. 


\section{$\underline{\text { Research Objective Four }}$}

To use the reflective information to identify the stages which comprise the transition out of the caregiver role.

After the caregiver experience is over, the individual begins the transition out of the caregiver role. This transition involves several stages and can be multidirectional, with each direction leading to a different result (see Figure 1). The transitionary period after the caregiver experience must not be overlooked or dismissed as insignificant, because its negotiation directly affects the individual's ability to adapt to life after caregiving.

The death of the Alzheimer's victim marks the beginning of the transition from the caregiver role. The intensity and variety of the emotions and feelings accompanying this death will vary among caregivers. However, every caregiver will experience some degree of relief in the swell of emotions. It is this feeling of relief that marks the second stage of the transition. The derivation of this relief varies among individuals. For some there is relief that their caregiver role is over. For others there is relief that their loved one is no longer suffering. Still for others, the relief comes from the knowledge that they can now move on with their lives. These sources of relief are not mutually exclusive and it is probable that individuals will experience some degree of each.

The feelings of relief directly lead to the next stage in the transition termed the stage of "current guilt." Individuals feel guilty about the relief that their loved one's death has brought. These feelings of guilt lead individuals to question their love and commitment to the Alzheimer's victim and subsequently to question their whole caregiver experience. 
This guilt-derived questioning leads to the reflection stage of the transition. During this stage the individual relives portions of the caregiver experience. This reflection is shadowed by constant self-questioning and self-doubt.

Up to this point the transition model has been linear in progression. The effects of the reflection on the individual will lead to the model's first branching. If the majority or entirety of the reflection is overcast by self-criticism, the individual will enter into the stage of "reflected guilt." If however the individual balances self-criticism with self-praise, he/she will progress into the stage of acceptance.

The stage of reflected guilt involves a preoccupation with things that went wrong in the caregiver experience, regrets and other negative components. As figure 1 shows, reflected guilt leads to a continuous circle involving anger, sorrow and longing. For the individual each emotion feeds off the other, entrapping them in a cycle of negativity and failure. Individuals entrapped in this cycle end up in a stage of unresolution, where they cannot find contentment and closure to their caregiver experience. These individuals are so preoccupied with reliving the past, that it consumes their present and future. As long as the individual remains in this cycle, they will not successfully complete the transition out of the caregiver role

In contrast, for those individuals who are able to move into the stage of acceptance, they have come to terms with their experiences and find some degree of contentment with their actions. This acceptance is supported by feelings of peace and hope, either involving spiritual renewal or future expectations. These individuals are able to live in the present and project into the future, while maintaining a balance of the past 
These individuals will reach the stage of closure, signifying the successful transition out of the caregiver role. 
Table 1

Descriptive Characteristics of Former Alzheimer's Caregivers

Categories

$$
\begin{aligned}
& \text { Frequencies } \\
& \mathbf{N}=\mathbf{2 0}
\end{aligned}
$$

Mean

Percentages

35-44

45-54

$55-64$

$65-74$

75-84

$85+$
2

1

9

2

3

3

Gender:

Male

Female
4

16

$20 \%$

$80 \%$

\section{Race/Ethnicity:}

Native American

African American

White

\section{9}

\section{Education Level:}

Finished High School

Some College/Technical School

College Degree

Graduate/Professional Degree

4

$20 \%$

$25 \%$

$6 \quad 30 \%$

$5 \quad 25 \%$

\section{Occupation:}

Professional

Clerical

Homemaker

Service

$\begin{array}{rr}12 & 60 \% \\ 5 & 25 \% \\ 2 & 10 \% \\ 1 & 5 \%\end{array}$

\section{Relation to Care Recipient:}

Wife

Husband

Son (Cared for Mother)

Daughter (Cared for Mother)

Daughter (Cared for Father)

Grandson

$40 \%$

$10 \%$ $5 \%$

$30 \%$

$10 \%$

$5 \%$ 
Table 1 (continued)

\begin{tabular}{|c|c|c|c|}
\hline Categories & Frequencies & Percentages & Mean \\
\hline \multicolumn{4}{|l|}{ Duration of Caregiver Role: } \\
\hline Less than 1 year & 1 & $5 \%$ & \\
\hline $1-5$ years & 7 & $35 \%$ & \\
\hline $6-10$ years & 7 & $35 \%$ & \\
\hline $11-15$ years & 5 & $25 \%$ & \\
\hline \multicolumn{4}{|c|}{ Time Since Death of Care Recipient: } \\
\hline Less than 1 year & 2 & $10 \%$ & \\
\hline $1-5$ years & 11 & $55 \%$ & \\
\hline $6-10$ years & 6 & $30 \%$ & \\
\hline More than 10 years & 1 & $5 \%$ & \\
\hline
\end{tabular}


Table 2

Caregiver Successes

\section{Predominant Themes}

1.) Kept loved one involved

2.) Treated person with dignity

3.) Learned not to argue/avoid conflict

4.) Got help/adult day center

5.) Learned/researched the disease

6.) Kept loved one safe 
Table 3

Caregiver Regrets

\section{Predominant Themes}

1.) Not getting help earlier

2.) Using a nursing home

3.) Lack of patience/understanding

4.) Not telling the person he/she had Alzheimer's disease 
Table 4

Caregiver Barriers

\section{Predominant Themes}

1.) Problems with nursing home

2.) Financially taxing

3.) Lack of support/criticism from family and friends

4.) Not knowing how to get help/access resources

5.) Stigma of Alzheimer's disease

6.) Juggling responsibilities/torn between victim and other family 
Table 5

Issues Following Death

Predominant Themes

1.) Maintaining same patterns

2.) Learning how to do things by/for yourself

3.) Loneliness

4.) Memories

5.) Guilt

6.) Could not go back to nursing home 
Table 6

Sources of Support

\section{Predominant Themes}

1.) Family

2.) Friends

3.) Church/Faith

4.) Formal Support Services

5.) Co-workers/Employers 
Table 7

Current Issues

\section{Predominant Themes}

1.) Anger

2.) Miss loved one

3.) Memories

4.) Guilt

5.) Identity Confusion 
Table 8

Perceptions During the Caregiver Experience

\section{Frequencies}

\begin{tabular}{lccccll}
\hline & $\mathbf{V M}$ & $\mathbf{S W}$ & $\mathbf{N}$ & $\mathbf{S W}$ & $\mathbf{V M}$ & \\
Anxious & 5 & 6 & 3 & 4 & 2 & Calm/Peaceful \\
Depressed & 4 & 7 & 3 & 2 & 5 & Content/Satisfied \\
Angry & 5 & 4 & 5 & 3 & 2 & Happy/Joyful \\
Empty & 6 & 1 & 5 & 3 & 5 & Complete/Whole \\
Isolated & 7 & 3 & 1 & 3 & 6 & Included \\
Inadequate & 9 & 3 & 1 & 4 & 3 & Adequate \\
Stressed & 11 & 6 & 2 & 0 & 1 & Relieved \\
Burdened & 9 & 4 & 4 & 2 & 1 & Free \\
& & & & & & \\
\hline
\end{tabular}

*VM = very much, $\mathrm{SW}=$ somewhat, $\mathrm{N}=$ neutral 
Table 9

Current Perceptions

\section{Frequencies}

\begin{tabular}{lcccccl}
\hline & $\mathbf{V M}$ & $\mathbf{S W}$ & $\mathbf{N}$ & $\mathbf{S W}$ & $\mathbf{V} \mathbf{M}^{*}$ & \\
Anxious & 1 & 0 & 0 & 3 & 16 & Calm/Peaceful \\
Depressed & 0 & 1 & 0 & 2 & 17 & Content/Satisfied \\
Angry & 0 & 1 & 3 & 2 & 14 & Happy/Joyful \\
Empty & 3 & 1 & 0 & 2 & 14 & Complete/Whole \\
Isolated & 0 & 0 & 1 & 3 & 16 & Included \\
Inadequate & 1 & 0 & 0 & 5 & 15 & Adequate \\
Stressed & 1 & 1 & 1 & 2 & 15 & Relieved \\
Burdened & 0 & 0 & 1 & 2 & 17 & Free \\
& & & & & & \\
\hline
\end{tabular}

${ }^{\star} \mathrm{VM}=$ very much, $\mathrm{SW}=$ somewhat, $\mathrm{N}=$ neutral 
Table 10

\section{Perception Comparison}

\begin{tabular}{llclc}
\hline Terms* & \multicolumn{2}{c}{ Perception During } & \multicolumn{2}{c}{ Perception After } \\
Bi-polar Adjectives & Mean & Mode & Mean & Mode \\
& & & & \\
\hline Angry/Calm\&Peaceful & 2.6 & 2.0 & 4.7 & 5.0 \\
Depressed/Content\&Satisfied & 3.0 & 2.0 & 4.8 & 5.0 \\
Angry/Happy\&Joyful & 2.5 & $1.0 / 3.0$ & 4.5 & 5.0 \\
Empty/Complete\&Whole & 3.0 & 1.0 & 4.2 & 5.0 \\
Isolated/Included & 2.9 & 1.0 & 4.8 & 5.0 \\
Inadequate/Adequate & 2.5 & 1.0 & 4.6 & 5.0 \\
Stressed/Relieved & 1.7 & 1.0 & 4.5 & 5.0 \\
Burdened/Free & 2.1 & 1.0 & 4.8 & 5.0 \\
& & & & \\
\hline
\end{tabular}

*Terms were ranked on a scale of $1-5$, with 1 being the most negative and 5 being the most positive. 
Table 11

\section{$\underline{\text { Caregiver Advice }}$}

\section{Predominant Themes}

1.) Get help as soon as possible

2.) Research Alzheimer's disease

3.) Take care of yourself as a caregiver

4.) Thoroughly investigate potential nursing homes

5.) Get a living will/attend to legal matters

6.) Keep a journal/diary

7.) Keep Alzheimer's victim involved

8.) Let the person do for themselves for as long as possible

9.) After experience, give back and help other caregivers 
Caregiver Reflection Model

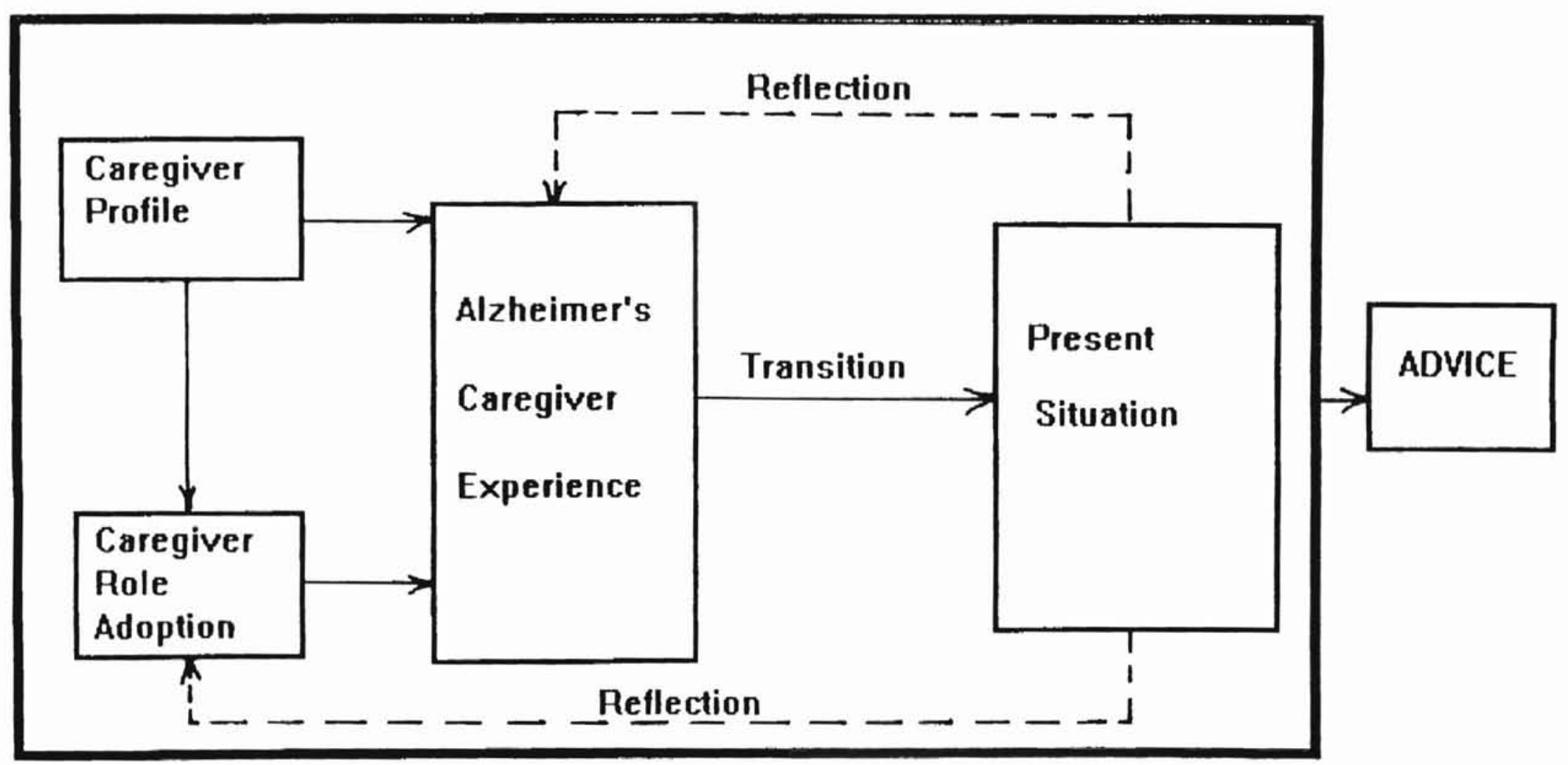


Figure 2

Alzheimer Caregiver Transition Model (ACT-M)

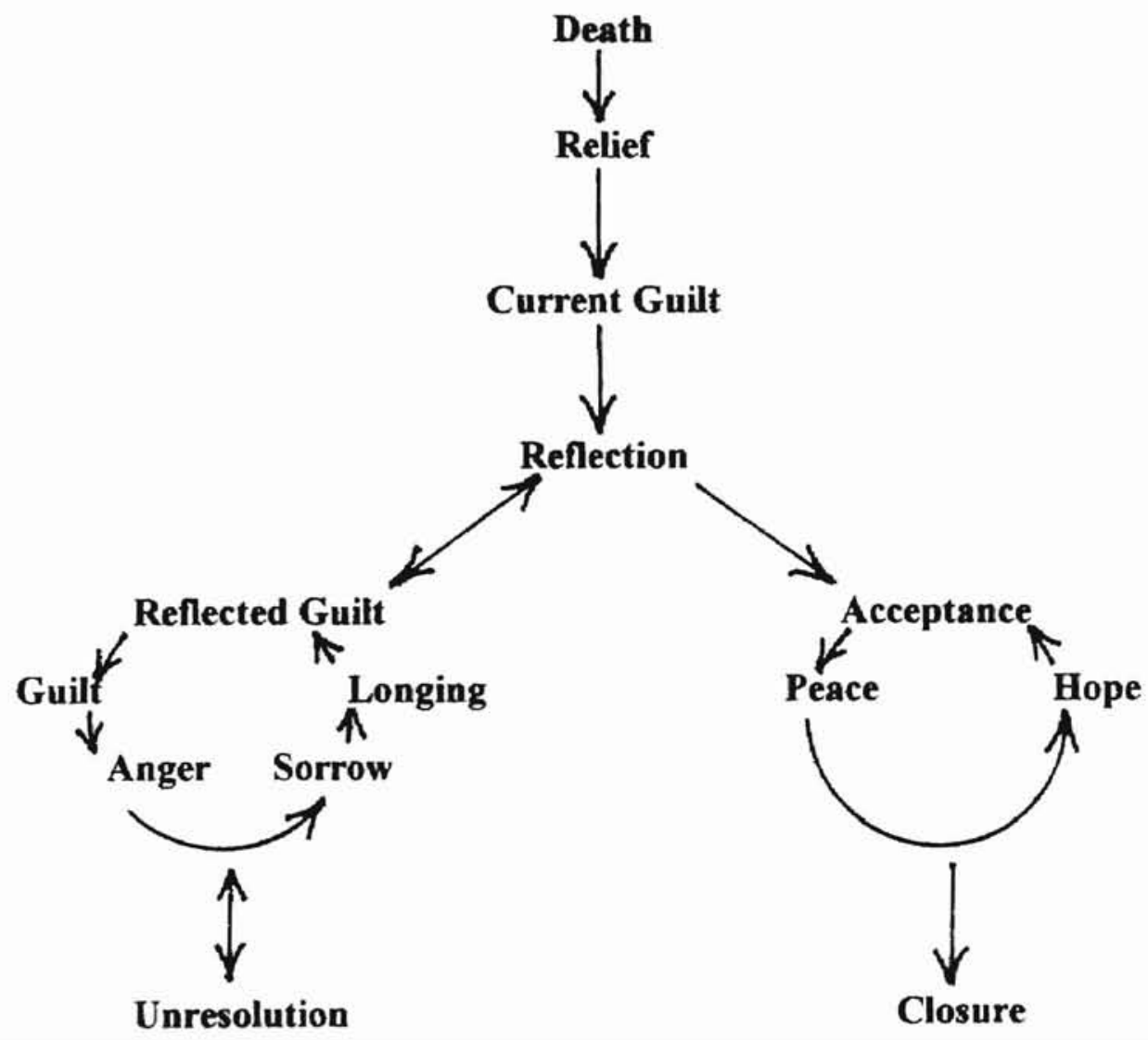




\section{APPENDIX C}

Institutional Review Board Form 


\section{OKLAHOMA STATE UNIVERSITY \\ INSTITUTIONAL REVIEW BOARD}

Date: $\quad$ October 1, 1999

IRB \#: HE-00-120

Proposal Title: $\quad$ "A REFLECTIVE STUDY OF ALZHEIMER'S CARE GIVERS"

Principal Dr. Joseph Weber

Investigator(s): Kevin Juozapavicius

Reviewed and

Processed as: $\quad$ Exempt

Approval Status Recommended by Reviewer(s): Approved

Signature:

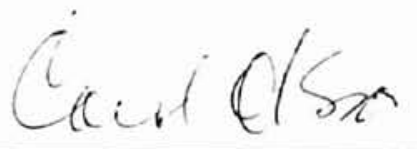

Carol Olson, Director of University Research Compliance

October 1.1999

Date

Approvals are valid for one calendar year, after which time a request for continuation must be submitted. Any modification to the research project approved by the IRB must be submitted for approval. Approved projects are subject to monitoring by the IRB. Expedited and exempt projects may be reviewed by the full Institutional Review Board. 


\section{VITA}

Kevin Juozapavicius

Candidate for the Degree of

Master of Science

Thesis: A REFLECTIVE STUDY OF ALZHEIMER'S CAREGIVERS

Major Field: Natural \& Applied Sciences

Biographical:

Personal Data: Born in Hinsdale, Illinois, On February 2, 1979, the daughter of Albert and Sharon Juozapavicius.

Education: Graduated from Glenpool High School, Glenpool, Oklahoma in May 1994; received Bachelor of Science degree in Biology/Pre-Med from Mary Washington College, Fredericksburg, Virginia in May 1998.

Completed the requirements for the Master of Science degree with a major in Natural \& Applied Sciences - Gerontology at Oklahoma State University in May, 2000.

Experience: Employed by Oklahoma State University as a graduate research assistant,1998 to present.

Professional Memberships: Sigma Phi Omega, Southwest Society on Aging. 